Utah State University

DigitalCommons@USU

5-1964

\title{
A Definition of the Role of Homemaker by Two Generations of Women
}

Genevieve Wise

Utah State University

Follow this and additional works at: https://digitalcommons.usu.edu/etd

Part of the Family, Life Course, and Society Commons

\section{Recommended Citation}

Wise, Genevieve, "A Definition of the Role of Homemaker by Two Generations of Women" (1964). All

Graduate Theses and Dissertations. 2289.

https://digitalcommons.usu.edu/etd/2289

This Thesis is brought to you for free and open access by the Graduate Studies at DigitalCommons@USU. It has been accepted for inclusion in All Graduate Theses and Dissertations by an authorized administrator of DigitalCommons@USU. For more information, please contact digitalcommons@usu.edu.

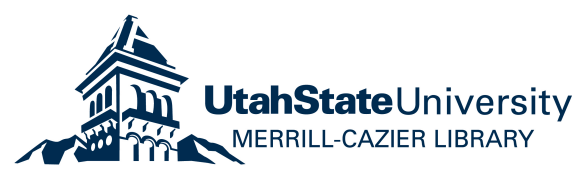


A DE FINITION OF THE ROLE OF HOMEMAKER

BY TWO GENERATIONS OF WOMEN

by

Genevieve M. Wise

A thesis submitted in partial fulfillment

of the requirements for the degree

of

MASTER OF SCIENCE

in

Marriage and Family Relations

Approved:

Major Professor

Head of Dopactment

Desm of Graduate Studies

UTAH STATE UNIVERSITY

Logan, Utah 


\section{A CKNOWLEDGMENT}

My sincere thanks and appreciation go to Dr. Don Carter for his inspiration and invaluable assistance in framing and executing this study, to Dr. Jay Skidmore and Mrs. Carmen Frederickson whose patience and suggestions were most helpful. Special appreciation goes to my husband, Paul, and to each of our eight children without whose support the entire project would have been impossible.

Genevieve M. Wise 
INTRODUCTION

Statement of the problem . . . . . . . . . . . 1

Hypotheses . . . . . . . . . . . . 10

REVIEW OF LITERATURE _. . . . . . . . . . . 13

Summary . . . . . . . . . . . . . . 33

METHODS . . . . . . . . . . . . 37

Sample . . . . . . . . . . . . 37

Instruments and procedures . . . . . . . . . 39

FINDINGS . . . . . . . . . . . . . . 43

Discussion . . . . . . . . . . . . . . 43

Summary . . . . . . . . . . . . . . 64

CONCLUSIONS, IMPLICATIONS, AND RECOMMENATIONS . . $\quad 67$

Conclusions . . . . . . . . . . . . 67

Implications . . . . . . . . . . . . 68

Recommendations for further research . . . . . . 70

LITERATURE CITED _. . . . . . . . . . . . 72

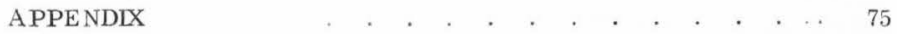




\section{LIST OF TABLES}

Table

Page

1. Percentages of mothers and daughters employed outside of the home

2. Comparison of LDS and non-LDS scores on the Motz

Inventory

3. Hours spent in activities outside the home by mothers and daughters, expressed in percentages of responses

4. Comparison of childhood environment of mothers and daughters whether rural, small town, or urban

5. Attitudes of mothers and daughters toward employment of mothers whose children are in school

6. Attitudes of mothers and daughters toward employment of mothers of preschool children

\section{LIST OF FIGURES}

Figure

1. Religious affiliation of mothers and daughters responding

2. Dominant religion in community where mothers and daughters were raised

3. Comparison of education---mothers, daughters, husbands

4. Comparison of mother's and daughter's scores on Motz Inventory

5. Mother's and daughter's responses to companionship statements on Motz Inventory.

6. Mother's and daughter's responses to traditional statements 


\section{INT RODUCTION}

\section{Statement of the problem}

This research is an attempt to investigate to what degree society, as represented by a selected group of married women, is accepting the role of the working wife and mother, and to what degree the traditional definition still prevails in the minds of two generations of women.

The roles women have played throughout the ages have been determined by the society of which they have been a part. Each influence that exists within a culture operates upon both men and women. Mores are more responsible than persons for the slow and often tedious progress to which women have been restricted. The subjugation of women has not ordinarily been the result of deliberate, organized plans, but has occurred because of the general reluctance of human beings to accept social change (16)

Present day attitudes toward women and their role in our society stem as far back as the ancient Hebrews and Greeks. In the Hebrew culture women were controlled by their father, an older brother, or husband. Their existence was restricted; owning property, commercial and political activities were denied them. They were expected to marry and raise large families (20).

The ancient Greek woman held an inferior status. She was not educated in any manner. She was not allowed to leave her home without her husband's permission, and then she must be veiled and accompanied by a slave. Kephart $(20$, 
p. 104-105) reported that, "Within the home the Athenian wife was expected to remain in her own quarters, and except at mealtime, when she joined her husband, her social contacts were almost nonexistent."

The Roman wife was not educated, but she was allowed to help entertain her husband's friends and commanded some respect as a homemaker. It was while Roman men were spending much time on the battlefields that women began to find some independence $(20)$.

One of the early influences which proved to be an obstacle to women's advancement was religious doctrine which enforced very rigid moral requirements. This was the influence of Aceticism which frowned upon the sex appeal of women as opposed to the oriental subjugation of women. Even though these doctrines were taught in an effort to develop high standards of religious and spiritual experience, they nevertheless had a degrading and stifling effect on women (16).

In spite of the fact that Christianity lowered the status of marriage and by doing so lowered the status of women, it's teachings gave women more protection and freedom than they had ever known before. The Christian philosophy of dignity of the individual opened a new era for women. The spread of Christianity gave them opportunities to be important in church activities in a way they had not yet experienced. Actually, monasticism was one of the first vocations that women were permitted to enjoy. As a nun, women were active in social work and philanthropy. They had certain ecclesiastical privileges in the convent that were denied to other women. The nun enjoyed social prestige. Although women were allowed some opportunity to be busy in church activities, they were still 
denied participation in civic functions, and could not hold public office $(16,20)$. It is interesting to note that in an early ecclesiastic conference, the bishops of the church debated whether or not woman had a soul $(12$, p. 257).

Through the Middle Ages, women were kept in the background while the men received notice. The idea that men could fight and so deserved more rights than women prevailed during the Feudal era, thus lessening women's property rights. The old English law discriminated against women and this trend traveled across the ocean with those who settled in America and became a part of the legal system in our country.

The Age of Chivalry, with its bent for romantio love, recognized the independent personality of woman. This period found acceptance of an association between men and women that approached equality and raised the status of women by creating a good emotional relationship that was not based on sex. The disorganization of the Renaissance gave a few women a chance for better training and more freedom. However, women remained socially inferior to men.

Protestantism advanced the status of women somewhat, and as the Feudal system began to crumble necessitating economic reconstruction, women started to contribute to the labor field. During the sixteenth century, we find women as craftsmen, laborers, artists, managers, even in politics to a degree. Our word "spinster" was derived from "spinner" which described a woman in the textile industry at that time (16)

Puritanism brought a bit more freedom for women, although they still remained very inferior to men. Kephart quotes Notestein's description of the 
Puritan woman as found in Studies in Social History:

Silence in women was esteemed a great virtue by poets, playwrights, and biographers.

Women were constantly praised for their good housekeeping . . a woman had to be thrifty, a virtue not overlooked by the makers of epitaphs, to keep children and servants under control, to provide clean and sweet linen, and to be ready at all times for guests.

For nothing were they more extolled than for obedience to their lords and for the patience that went with obedience. Biographers liked to expatiate on this virtue in wives, and clergymen in funeral sermons alluded to it, perhaps with a glance at a certain pew. Mothers instructed their daughters in the duty and set an example to them.

But in no way was their subordination more evident than in their want of influence over them. Too fearful they were of their lords and masters to venture upon disagreement. When Lady Harley wished her husband to do something she would ask her son at Oxford to raise the question with his father. $(20$, p. 130131)

Queen Elizabeth exerted an influence upon the weakening of women's subordination to men. During her time, interest was stimulated in the relationship of the sexes, and this was the topic of discussions, books, and drama.

The organizing of a new world forced a new order, and the emancipation of women took great strides with the development of society in America. Conditions were favorable here for a change in the relationships between man and woman. The crossing of the Atlantic ocean created a social crisis, and the move to the Frontier in America created an even greater one. Mores tend to collapse in the face of social crises, so it is at times like these that changes in the mores are made. Nowhere were the traditions and customs which maintained social inferiority more incongruous than among the American pioneers. The conditions of life for these stalwarts were such that emphasis came to be upon the value of the 
individual, whether man or woman. Women gradually were becoming to be regarded as personalities apart from any sex characteristic (16, p. 187-188).

The Industrial Revolution forced distinct changes in the entire society. Komarovsky writes:

The old system began to change not because a group of emotionally disordered feminists succeeded in hoodwinking or bullying the Western World, but because the Industrial Revolution radically reorganized the whole of our society. $(21$, p. 50 )

During the 1860 's women were working in factories, and there was more general acceptance of this fact by society. Because she was becoming independent of father or husband for support, she began to be more particular about marrying. Marriage was no longer entered into as an expedient. Now it was something she chose for love and happiness.

Interestingly enough, the emphasis was more upon discouraging women from entering the professions at this time than it was to discourage them from entering factories. The general feeling was that women were naturally unfit for such vocations. "Feminine ambitions were the abandonment of divine decree registered in the physiological structure of the woman." (16, p. 313)

From the beginning of this century there has been a change in feeling toward women, a new outlook. The unprecedented recognition of the value of women has measured, perhaps better than anything else, the progress women had made in their advance toward social equality with men. World War I brought mushrooming opportunities for women in vocations. The effect of this on women was to further break down the barrier between the sexes. There was increased 
tolerance of women in industry, and a much greater appreciation of her adaptability and efficiency which marked a change of mind on the part of both sexes (16).

The strides that have taken place in the emancipation of women in the twentieth century are most significant. Women have reached a point of nearequality with men that has not been known before in history. Not only is this true in America, but also in countries all over the world. The effects of this tremendous change in the lives of women has become general only since 1920 , however (12). Now, women are free to define themselves, not in terms of the masculine influence they have in their lives, but in terms of what they want as individuals. One writer said that now they "can become fully human since selfdefinition is the capacity marking human beings off from the rest of the universe." (12, p. vii)

At the turn of the century the expected role of a young woman was that she would marry, bringing to that marriage a dowry of skills such as cooking, baking, canning, and preserving. It was she who would be responsible for keeping the family clothed by plying her needle. She was mother, nurse, gardner, teacher, besides being an independent production unit all within her own home (16). In this way she made a major contribution to the economy of her family, and she shared the responsibility of caring for and supporting the family with her husband. According to Komarovsky,

We think of our historic past as a period of clear-cut division of labor between the sexes: man the provider, woman the homemaker. Actually, women were also providers through the multitude of goods and services supplied by home industry. (21, p. 50) 
The advent of technology in our country, and its accompanying massproduction of the necessities of life, as well as labor and time saving devices for the home, has taken most of the traditional productive functions outside of the home. Today's married woman is using frozen food, packaged baking mixes, and canned goods from the grocer's shelf. She patronizes the local supermarket where her table can be supplied with prepared and packaged foods that free her from many hours of work in the kitchen. She enjoys services of the laundromat, dry-cleaner, bakery, delicatessen, ready-to-wear shops, and beauty parlors. Even the chore of ironing has been minimized by the advent of drip-dry fabrics that need little or no pressing. The popularity of paper napkins and contour sheets demonstrates her acceptance of shortcuts and commercial ingenuity.

We live in an era when the expansion of industry and the ingenuity and inventiveness of American genius are creating in ever increasing numbers, commercial products which are amazingly capable of performing tasks that heretofore have been woman's domain, her sphere of excellence. Her skills in creating fine pies, cakes and rolls, with the accompanying feelings of accomplishment can be duplicated today by any child who can read and follow simple directions. Complete dinners can be prepared by male or female at almost any age merely by unwrapping a package and setting the oven timer. Where is any woman who based her feelings of pride and accomplishment on culinary skills going to find her feelings of worth under these conditions? Possibly there is not a beef stew on the market at the moment which equals the excellence of the one mother makes, but who is to say how long it will be before even this is available? 
Our economy has shifted from family centered to factory centered, and according to Nye,

These advances have transformed the mother from a vitally important economically contributing member to the family to one whose utility in this respect sometimes approaches the trivial. $(26$, p. 4)

As a result, women's dilemma seems to be that she is left not only with more time on her hands, but without a well-defined role to fill.

The advance of science and technology has not only simplified the duties of the homemaker, and freed her from many hours of hard work, but also has created job specialization and increasing opportunities for employment of women (26).

Contrast the change in the lives of women today from their earlier roles as the traditional homemaker, to the modern homemaker who is also busy outside of the home. In 1890, 4 million women in paid employment accounted for about one-sixth of the workers. In 1956, 22 million working women comprised almost one-third of the civilian labor force. In 1890, about one-sixth of all women 10 years or older were working. In 1956, one-third of all women 14 and over were in the labor force in any given month. At the close of the last century, about half of the adult women never entered paid employment. Now at least 9 out of every 10 women are likely to work outside the home in the course of their lives (37, p. 10). Today 24 million wornen comprise one in three of our country's workers (1, p. 63). Before World War II, there were over 13 million women working. This was 22 per cent of all workers and 24 per cent of all women. 
By April 1962, over 24 million women were working, and this was 34 per cent of all workers and 35 per cent of all women $(17$, p. 3). Of those women who are working, 46 to 55 per cent are married (17, p. 5).

The average participation of women in the work force at the turn of the century was 11 years, compared to the average of 25 years that today's school girls may spend in work outside the home. In 1890, 7 out of every 10 women who did work outside the home were under 25 years of age, and in contrast, among today's working women, 6 out of every 10 are married, and 5 out of 10 are over 40 years of age. Nearly 2 out of every 5 mothers whose children are of school age are in the labor force (37, p. 10). More than 3 million of our workers are the mothers of young children (12, p. 191). By 1970, women are expected to make up 40 per cent of the total labor force $(7, p .1)$. It is no longer a question of whether women should or should not work. Despite the prevalent stereotyped concept of women's traditional role as a wife-mother, and homemaker, the facts show that women--wives and mothers--ARE working outside the home. Rollins (30) found that there was not much difference in numbers of married women who were earning in 1920 and in 1960. She found the difference to be that in 1920 women could coordinate homemaking and earning right in their homes, but the wives and mothers in 1960 were performing these two functions in two different places. The mothers in both instances were contributing to the care and support of the family. Could this possibly be modern women's way of helping her husband care for and support their family?

According to the Report of the President's Commission on the Status of Women 1963 s 
Consumer goods have always been conspicuous in the United States national production and the American woman has been in large part responsible for their form. But over the last 60 years, her ways of supplying family needs have changed out of all recognition. (1, p. 60)

It is not unlikely to suppose that household equipment will continue to improve, and with that the accompanying increase in the shift of production to the factory and services. Mothers and women of all ages will very likely be drawn into the labor force in even greater numbers. According to Leser, the trend of production from home to factory is irreversible, and it seems inevitable that women will follow their tasks to the factory and office $(19, p .109)$. Somewhere in all of this must come conscious recognition by society itself of the fusion, if you please, of the homemaker and provider roles for women.

\section{Hypotheses}

It is the purpose of this research to study whether the concept of "provider" is becoming an accepted part of the definition of the modern homemaker. "Provider" is used in the sense of the wife sharing to some degree the husband's major responsibility of providing for the family. Because of the large numbers of women who are in the labor force, and because of the conflict this reality causes with the traditional concept that women's place is in the home, it can be assumed that there will be degrees of role definition that range from purely contemporary to the purely traditional role. This investigation will be an attempt to determine whether any significant trend toward the contemporary definition can be recognized from one generation of women to the next. 
The large percentage of women over 40 who are working today (50 per cent) makes it possible that the mothers will feel more inclined toward contemporary role than will their daughters. The daughters are involved at the moment with raising their families and have possibly not given much thought to going back to work later on. On the other hand, girls who have grown up in an atmosphere more accepting of the working mother could be assumed to have more contemporary attitudes than their mothers, even though the mothers are working in larger numbers than the daughters.

The basic hypothesis is that in the sample selected for this study there will be no significant trend away from the traditional role toward the contemporary role in either the mother or the daughter groups, and that there will be no significant differences in the attitudes of the mothers and the daughters.

A secondary hypothesis to be examined is that the responses of the women-their expressed attitudes--and their actual participation in either a traditional or contemporary role will not be in agreement. Other researchhas demonstrated that, in matters of this kind, there exists a difference between the stated and the actual patterns of behavior (29). It seemed desirable to investigate the possibility of such a dichotomy in this situation.

The orientation of both groups of women will be studied in the light of several different variables. The minor hypothesis is that there will be no significant influence upon women's contemporary or traditional role perceptions by such variables as: 
a. education of husband

b. occupation of husband

c. education of wife

d. wife's work orientation (work oriented--not work oriented)

e. wife's previous work experience

f. whether wife is now employed

g. occupation of wife

h. community in which wife was raised--rural or urban

i. ages of children

j. attitudes toward employment of mothers of preschool children

k. attitudes toward employment of mothers whose children are in school 


\section{REVIEW OF LITERAT URE}

A review of the literature produced several studies that are pertinent to this research. These fell into various categories, the greater number directed toward the concept of feminine role. These included studies from the point of view of women, both young and old, as well as adolescents and men's perceptions of women's roles. Other studies eye the relationship and problems in middle age, the maternal employment and marriage interaction, a new expecta-

tion for father's role, romanticism in marriage, disillusionment in marriage, and the effect of mother's employment upon child rearing. A final study examined changes in family patterns and problems in a culture similar to the one in which this study is centered.

Weiss and Sameison (36) investigated the contribution of the social roles of American women to a sense of usefulness and importance. The purpose of this study was to examine the extent to which the major social roles available to women provide them with a basis for feelings of worth. Emphasis was on the housewife and employed woman.

A sample was selected on a probability basis to be representative of all women age 21 and over, living in the United States. Five hundred and sixty-nine women were interviewed, and asked to name some of the things they did which made them feel useful and important. Social roles were developed under the headings of housework, job, family, and informal interaction outside the home. 
A rather substantial proportion of women in the older age groups said that nothing made them feel useful and important. Three factors seemed to be of primary importance in determining how a woman made her evaluation of her role. They were: education, her situation in life in terms of age, employment, marriage, children; and, if she is employed, the kind of job she holds.

Conclusions of the study were that women who are unmarried particularly middle-aged women) will want careers or other meaningful social roles outside the home, but married women will only infrequently be motivated to seek careers because of the emptiness of housework. The type of job is very important. The higher the achievement and skill required for the job, the more it contributes to her feelings of worth. Indications were that the jobs available will determine to a large degree whether women will want to work or not.

Older single women, according to this research, are unlikely to refer either to housework or to employment as a base for feelings of worth.

Marriage seems to set a condition in which housework takes on and maintains value for the majority of women. "Doing for one's self" seems to pall quickly, but keeping house for self and husband continues to be a source of worth even after children leave home. (36, p. 365)

Weis and Samelson suggest that the problems of the older woman in finding a place where she feels some personal worth are largely caused by our American Culture. The children move away because that is what our culture expects them to do. In her childless home she has no better future to work for, and "because we see life in terms of building for the future, her daily tasks have lost much of their meaning. " (36, p. 364) 
Weil (35) considered factors permitting compatibility between career performance and the homemaker role. She hypothesized that a woman will perform or plan to perform in both the traditional and career roles when the husband's attitude supports the decision, when employment is available, when she has achieved a "high" educational level, and when the husband will accept obligation for helping care for children. This study was an attempt to discover the factors that are related to actual or planned participation of married women with children in the labor force, in order to establish a workable arrangement between performance in the labor force and performance as a mother. The sample population was 200 married women with children living in a housing development in a suburban town in New Jersey. Respondents were home owners, white, of various religious faiths, median age was 36 years, and median income was $\$ 7900.00$ per year. Half of the sample were working or planning to work.

Homes were visited and the interview scheduled, and the Motz Inventory were administered. Findings showed that the career orientation of the wife and favorable attitude of the husband were determining factors in influencing actual or planned participation in the world of work. Two other influential factors were the husband's help with child care and the children being of school age. The latter was only a temporary inhibiting factor. Weil observed that many of the reasons given for employment or planned employment can be described as a part of the process of continuous personal development.

An investigation of attitudes of women in a small southern community toward the gainful employment of married women was done by Glenn (14) on a sample of 247 
randomly selected households. Each was canvassed and a census card filled for it. Respondents had to be married or have been married and had to be assuming the major responsibility for the household.

Questions were constructed to identify attitudes of respondents regarding justifiable reasons for a married woman's working. Such reasons were suggested as economic, dislike of housekeeping, desire to use special skills, use education. Questions also were prepared to identify attitudes toward the gainful employment of women under the following conditions: have no children, have children under school age, children grade school age, and children high school age.

The respondents' willingness to approve working seemed to depend on two considerations: the reason given for her employment or the goal she wished to attain, and the presence of children in the home and their ages.

Over 90 per cent approved the wife working if earnings were needed for necessities of life, to help pay accumulated debts, to help husband finish education, or to help the family buy a home. From 80 to 90 per cent approved her working in order to buy special needed equipment, help care for dependent relatives, work with the husband in his business, or if there were a need in the community for her special services.

Very few respondents approved working in order not to waste education, or because the wife considered the work more respectable than housewifery, or because they felt that gainful employment had more prestige. This study indicates that mothers in this small community have moved away from the completely traditional conception that a married woman's place is in the home, but they still 
feel that the mother of children up through grade school should only work when it is necessary.

Gray's research (15) was based on the hypothesis that the conflict between a woman's conscious wishes or unconscious needs and the various roles expected of her by society, are common causes of anxiety. Dr. Gray is a medical doctor who specializes in psychotherapy of family confusions and anxieties. He had 203 mothers of children from 3 to 8 years of age estimate how many mothers would fall into various classes--desiring to spend what part of the day with their children.

1 or 2 hours a day weekdays

3 or 4 hours a day weekdays

5 or 6 hours a day weekdays

7 or 8 hours a day weekdays

9 or 10 hours a day weekdays

11 or 12 hours a day weekdays

Total estimate, weekdays

$-\%$
$-\quad \%$
-100

$\%$; weekends

$\%$; weekends

$\%$; weekends

$\%$; weekends

$\%$; weekends

$\%$; weekends

$\begin{array}{r}\% \\ \hline \% \\ \hline \% \\ \hline \% \\ \hline \% \\ \hline\end{array}$

$\%$; weekends $\overline{100} \% \quad(15$, p. 179)

After estimating how many mothers they thought would fit into each category, Gray asked which category they belonged in. His sample consisted of 25 mothers from the Oak Co-operative Nursery School, 18 mothers from Star King Parent Child Workshop, 40 mothers from psychotherapy for anxieties, and sundry mothers not in schools or psychotherapy. The results showed that the estimates of 203 mothers yielded a grand mean of 6 hours a day that they would choose to spend with their children--plainly much less than mothers are obliged to spend.

Hatch and Hatch (18) made a study to discover to what extent articles appearing in magazines designed to serve the interests of working women, present a constructive approach to the recognition and solution of the problems of the married women with regular paid employment outside the home. They sampled 
Mademoiselle, Glamour, and Charm magazines for the year 1956 and 1957.

Each publication had a circulation of 550,000 or more. Each issue was analyzed for articles dealing with problems of married women employed outside of the home.

There were 35 issues in all. The evaluation showed that the articles generally failed to deal realistically with the lack of clarity of goals for women. They failed to recognize the need for early choice of vocational training that will lend itself to family life. They did not point out the need for some agreement between husband and wife on the objectives of the wife working. The articles didn't discuss problems of maintaining work skills during enforced unemployment, or problems of loss of senority, or of slow advancement.

In no case was a problem left without a solution, and in all but two articles, the attitude of the author was one of unquestioning optimism and hope for happy solution to the problems of married working women. Many articles reveal an agg ressively crusading spirit, which tends to emphasize the need for women to fight prejudice against married women workers. The conclusions of the authors suggest that opportunities for women to work have expanded in the past hundred years, and that possibly the goals for attainment of recognition, creative expression, and security that were formerly identified with marriage and home may now be linked with paid employment outside the home.

The feminine sex role as perceived by 85 college women for themselves, their ideal woman, the average woman, and men's ideal woman, was the object of study by Fand (11) in 1955. A questionnaire was offered four different times for responses from varying points of view. The first offering requested a response 
that was their true opinion. On the second offering responses of the ideal woman were requested. The third offering asked for responses of the average woman, and the fourth of men's ideal woman. The findings seemed to show that a woman's self concept plays a determining part in her choice of a certain version of the feminine role. Happiness of family life, position in the family, parents ' educational and economic status, religion, and size of home community were the most influential factors in developing her self concept according to this study.

The vocational roles of older married women are investigated by Steinman (33). The purpose of this study was to investigate the concept of the feminine role held by mothers of college age girls in 51 middle class American families. The sample consisted of college girls ages 17 to 22 , in a college in suburban New York City, and their mothers. A questionnaire was used which included the Fand Inventory, a measurement of the degree of self or other oriented values. Ten of the sample were interviewed personally.

Most of the mothers were wary of combining vocational pursuits with marriage. The mothers did want expression in terms of their families as well as through their own individuality, but didn't consider a vocation necessary to accomplish this. They almost universally felt that the family needed mother at home, that husbands objected to their working, and that they lost their personal freedom if they worked. Those wives who were working, but not out of financial necessity, seemed to feel that unless she is vocationally active and creative, she can't be an interesting and stimulating woman. Generally among these older women there was an acceptance of the woman's role of homemaker, and the impression that 
these women don't think it worthwhile to alter their status.

Schneider (31) surveyed the relationship between identification with mother and home, or career orientation in women. His hypothesis was that there is a relationship between a daughter ${ }^{8}$ identification with her mother and similarity of the daughter's orientation to her perception of her mother's orientation. Subjects were college seniors grouped as home oriented or career oriented on the Strong Vocational Interest Blank. Two groups were matched as to socioeconomic background, religion, intelligence, and age. Two specially designed inventories provided data. Point-biserial correlations failed to yield any statistical significance, and Schneider concluded that identification with mother is not clearly or markedly related to a daughter's orientation toward homemaking or career. This research was done from the standpoint of analytic and learning theory philosophies.

Payne (28) executed a study which grew out of the recognition of the trend for women both married and unmarried to enter the labor force in ever-increasing numbers. The study was intended to discover whether youngsters have established ideas on the subject of married women working, and if so, what their ideas are. Variables considered included rural-urban, younger and older adolescents, boys and girls, high and low socio-economic levels, and those having working mothers or mothers who had not worked since marriage.

Subjects were 901 students in the eighth and twelfth grades in Gainsville and Hall Counties, Georgia. All data obtained were responses on printed questionnaires by individual students in their classrooms under supervision of teachers in 
all schools on the same day. Boys were asked if they expected their wives to work outside the home after marriage; and girls were asked if they expected to work before marriage and if they expected to work after marriage.

Results showed that 77.9 per cent of the boys in the sample did not expect their wives to work outside the home, while 91.9 per cent of the girls did expect to work outside the home. Observable relationships between the rural and urban, or socio-economic level, grade in school, or mother's working or not, did not develop. More urban girls expected to work than rural girls, and more younger girls expected to work than seniors. Payne concluded that girls appear closer to reality than boys, more prepared to meet the present trend for women to be employed in our country. The conflicting attitudes between the boys and girls could lead to confusion and disappointment in their marriages later. The conflicts of traditional and emerging social values are very real in this study.

Axelson (2) reports research on the marital adjustment and the marital role definitions of husbands of working and nonworking wives. The purpose of the study was to explore husbands' attitudes toward the working wife and investigate the relationship of the husband's marital adjustment to working and nonworking wives.

The sample was obtained by taking a 25 per cent sample of the blocks in a small western town and sampling 50 per cent of the dwellings in the sample blocks. Questionnaires were mailed to husbands residing with their wives and 122 usable forms were returned. This was an 80 per cent return. Of the sample, 37 per cent had working wives. 
The results showed significant differences in the perception of circumstances wherein a wife should work, existing between the husbands of the working and non-working wives. Husbands of the working wives had a more liberal view of the wife's employment, economic equality, and privilege of individual sexual expression. The majority of husbands expressed strong reservations about the effect of her employment on the traditional role of wife and mother. Husbands did not apparently feel any threat to their masculine status from their wives working.

According to this research, the working wife continues to be perceived as a threat by the male in our society. Males believed children suffered when the wife worked, and feared the wife would increase her independence and threaten his culturally defined dominance--especially if she made more money than he. The husband of the working wife, however, sees the working wife as less of a threat than the husband of the non-working wife.

Stuber (34) studied feminine roles from the husband's point of view. The purpose of the study was three-fold: to investigate the degree of understanding of young and mature husbands of their wives' attitudes toward role-related activities, and to determine whether young and mature husbands differ in their degree of understanding of their wives' feelings; to investigate the attitudes of young and mature couples toward the "ideal wife"; and to see if young and mature husbands differ in the degree of satisfaction provided by their wives. Stuber also hoped to provide clues to the changing role of the wife and the conflicts and pressures experienced by her in our culture. 
Two groups of married couples in which none of the wives was employed comprised the sample. All couples had one or more children. They had been married only once, and there were no more than 8 years difference between the age of husband and wife. The young group of 35 couples were from 20 to 35 years old. The older group of 35 couples were from 50 to 65 years old.

Two questionnaires were administered, each asking the same questions about four role areas designated as housekeeper, child rearing, companion-partner, and personal development. In the first questionnaire wives were asked to answer how they actually felt, and husbands were to answer how they thought their wife felt. In the second questionnaire the wives were asked to mark how they thought they should feel in order to be an ideal homemaker, and husbands were asked to respond in terms of their ideal wife.

The study showed that each of the three factors examined contributed to feminine role conflict. There was lack of understanding of both young and mature husbands of their wives' attitudes toward role-related activities. There was lack of agreement of both generations on the "ideal wife" roles. There was apparent dissatisfaction of both young and mature husbands with their wives' role performance.

Yarrow (38) studied some aspects of child-rearing in families of working working and non-working mothers. She hypothesized that the mother's gratifications and frustrations in her other adult roles, her achievement needs, and her feelings of self-fulfillment influence her functioning as a mother and affect 
what is mediated to the child by the mother's child-rearing practices.

The sample was 50 employed and 50 non-employed mothers. The two groups were compared on family composition and social class. All of the women were from families where working was not a necessity, but a choice. Families were all white, intact, and there was a male wage-earner present. Each family had from one to four children, and the mother was interviewed about at least one child in each family. In determining whether a mother was working or not, Yarrow established 28 hours a week as constituting employment.

The variables considered were: mother-child separation, personal satisfaction, personal economic stress, substitute care for child, and changed mother-father role.

Subjects were asked how they felt about "a woman's place is in the home," and the relative achievement needs of men and women. They were also asked how they felt about the acceptability of either sex showing dependency on the other. Responses were rated either equalitarian or traditional.

Results showed that 15 per cent of the women were rated traditional on two or three dimensions, 44 per cent were rated traditional on one dimension, and 41 per cent were rated traditional in none of the dimensions.

Yarrow concluded that a mother's decision to work lies outside of this area she was investigating. She theorized that maternal employment is not a single condition of mothering but rather a set of conditions that vary greatly from case to case. In one comparison the difference between the groups was statistically significant at the 5 per cent level. This was the mother's confidence about her role 
as mother. Working mothers more frequently than non-working mothers express misgivings and anxious concern about their role, often by explicit questioning and worry as to whether working is interfering with their relationships and the rearing of their children. Non-working mothers who want to work, but do not work "out of a feeling of duty" showed the greatest number of problems in child rearing. A mother's success in the dual role seems to depend on social, familial, and personal factors. Her fulfillments or frustrations in non-mother roles are related to child-rearing characteristics.

Research by Blood and Hamblin(3) attempted to test some hypotheses regarding effects of the wife's employment on the power relationship between the husband and wife as shown in marital attitudes and behavior. Their basic hypothesis was: The husband-dominated family becomes more equalitarian as a result of the wife's employment outside of the home.

The sample included 350 couples. Of these, half of the wives were employed full-time outside of the home. Each couple had been married for from 1 to 6 years, and the wives had been in their present role, whether working or not working, for at least 1 year.

The working and non-working groups were compared on several variables: socio-economic class, absolute education of the wife, relative education of husband and wife, independent unearned income of wife, number of children, religion, number of years married, and number of years wife had been in her present role.

The results of the study showed husbands and wives in both working and non-working groups presenting a pattern of getting the necessary tasks done by 
whoever was available. Neither partner felt superior or inferior no matter who did what. The families studied appeared to be very equalitarian. This study showed husbands and wives in the sample making decisions on a give and take basis and suggests the importance of viewing the family as a primary group governed by moral imperatives. In other words, each was willing to do whatever needed to be done for the family.

In 1950, Dornbusch and Heer (10) computed ecological correlations between level of income and female participation in the labor force, supporting the hypothesis that white females were changing their evaluation of work (as determined by a previous study in 1940). The previous negative correlations for white women now tended to be positive. For non-white women the tendency was beginning to be found, particularly among young adults. Thus, the values of non-white women apparently are following the same pattern of change as those of white women, but with a time lag of more than a decade. Dornbusch and Heer predict that there will be no correlation for the white women between participation and income by the year 1960

Nye (25) tested the relationship between employment status of mothers and marital permanence, satisfaction, and happiness against the variables of upper and lower socio-economic strata, large or small families, and original or remarriages. His sample was obtained by drawing random sub-samples of 100 women each. This was done in order to prepare two scales, an argument scale and a marital adjustment scale for a previous study (27). One sample was drawn and analyzed and then another drawn and analyzed. In developing the marital 
adjustment scale, 13 samples of 100 mothers of children in grades 1 and 10 of all public and parochial schools in three small Washington cities were drawn. These mothers had been married from 7 to 25 years. Mean age of the mothers with children in grade 10 was 40 and of children in grade 1 was 31 . Data were collected by mailed questionnaire and responses were received from 78 per cent of the sample.

Nye found that husbands of women employed full-time generally approve of the arrangements that have been made. Differences in marital adjustment are greater in low economic groups and almost disappear in the higher occupations and higher education categories. There is less likely to be an adverse effect on marital adjustment when the mother is employed from families involving remarriage or high socio-economic status. Conversely, marital adjustment is more likely to be adversely affected by the mother's working in families of low socio-economic status and in first marriages.

The picture of the empty nest and the problems it implies are examined by Brayshaw (4) in an address to the Groves Conference, Baltimore, April 1962. He discusses the modern problem of parents whose children are grown and gone from the home--that of finding worthwhile activities and a raison d'etre when they are once again thrust onto their own resources. Things were very different before this century when parents went on having children until they were middleaged, and the children were not all gone from the home until the parents were elderly.

We spend our lives working to provide a home and training for our children 
believing that this is our purpose in life, then when the children are gone, we find ourselves without a purpose in life. Brayshaw suggests that this is the time to explore the magical--the religious, artistic, and beautiful. This is when we need to explore the depths of poetry, music, literature, truth, to let our imaginations soar. He suggests that this is a time for renewing our outlook on life, for finding and setting new goals, for becoming interested and interesting, Cuber and Barroff (9) made a study to find out whether the concepts of professionals are reasonably in line with laymen's own perceptions and whether the imagery of the professionals corresponds to the imagery of the subjects about the same matters.

Subjects were upper middle class men and women 35 to 55 years old, white, middle class, non-clinical. There were 437 in all. Not more than 9 per cent of the total population was represented by this sample. All couples had been married for at least 10 years, said they had never considered divorce, and were thought by family and friends to be normal American families.

The method used was an unstructured, lengthy, intimate interview.

Evidence showed very few deeply satisfying relationships at this age in this particular group of people. Of the good man and woman relationships that did exist, there were a high incidence of them outside of marriage. Those marriages that did survive without satisfying relationships did so largely because of tradition, practical convenience, austere social sanctions, and other similar reasons. There were a few marriages in which there was a qualitatively good relationship. 
Hobart's (19) purpose was to evaluate some data on the question of whether the unrealistic idealization induced by the romantic love emphasis in our culture would suggest a resulting dissillusionment reaction in marriage.

The sample consisted of 78 favorite date, 66 going steady, 54 engaged, and 60 married couples which were obtained in a non-random sampling of students and their off-campus dates, fiances, and mates, at a West Coast sectarian college. All sample couples consisted of at least one member who attended the same small relatively expensive and selective private denominational college.

Personal responses of each of the couples to questions were rated on a 5 -point Likert scale.

Findings showed the transition to marriage associated with more disillusionment than any other courtship transition, but findings are more definite for male subjects than for female subjects. It appeared that emphasis on romanticism in the American culture which is definitely associated with advanced courtship, may in effect be preparing engaged couples for disillusionment in marriage. Hobart discovered a tendency for post-marital disillusionment for men to be associated with some romanticized areas, but no comparable tendency for women. This leads one to conclude that perhaps romanticism during courtship is more characteristic of males than of females.

Pineo (29) reported the changes occurring in 1000 couples' marriages between the early and middle year periods. He reported on the results of a study by Burgess and associates in a third wave of interviews with the same couples--a longitudinal study. At this point the couples had been married for as long as 20 years. 
Pineo discussed the findings that couples had moved to a less traditional position, but at the same time the husband was more dominant and the wife more submissive. Both parties in the couples agreed that this was not the ideal situation. Pineo found that high income families appeared to be more authoritarian, but at the same time they had a greater acceptance of a more liberal family relationship. This points out the paradox that acceptance of a liberal ideal and the actual changes in behavior are not necessarily related. The study showed that gradually decreasing marital satisfaction was the pattern in the marriages studied. The loss of marital adjustment was not accompanied by loss of personal adjustment. A different rate of disenchantment was found in those who stay married and those who finally divorce.

Mogey's proposition (23) that the role of the father in the family is a most important factor in family stability was presented in a paper before the American Sociological Society in Washington, D. C., in September 1955. The hypothesis was that in the nuclear family, participation by the father counts for more towards family stability than a strict, legal, traditional type of authority behavior. He suggested that the father role is the most rapidly changing role in the modern family. The change he described as one changing from authoritarian to active helper who participates in all the tasks of the household. He based the cause of the change upon loss of family functions and the emergence of what he termed the nuclear family as a distinctive group. He saw the changes in family function not as disintegration of the family, but as a condition of disorganization with the family attempting to redefine itself and its functions. 
Mogey claimed that the participating role of the father gives the family a new stability. The shorter work week, home ownership, single family homes, and house-repairing all make the word "companionship" too passive to describe the relations of the modern father and his family. The word Mogey preferred to describe this new father position was "participating."

The Canning (5) study focused on the changing patterns and problems of family life in Provo, Utah, comparing three generations from 1905 to 1955 . His purpose was to study the changes in the institution of marriage and family living and to determine and describe patterns of change and/or stability in courtship, marriage, and family living in Provo, from 1905 to 1955 . His sample was selected from the 7800 couples who obtained marriage licenses in Utah County, and who were living in Provo in 1955. Couples in the sample numbered 238 which included 63 families participating in the older group, 83 participating in the middle group, and 93 from the younger group. The couples in the older group had been married between 1905 and 1910, the middle group between 1925 and 1930 , and the younger group between 1945 and 1950. One hundred thirty-three families were personally interviewed in their homes. The remaining 105 members of the sample responded to questionnaires.

Both major hypotheses were substantiated by the study. The first hypothesis stated that the institutions of marriage and family living have changed markedly in Provo, Utah, in the fifty years between 1905 and 1955, and that in general this change was from the authoritarian, father-dominated type to a more democratic type of marriage and family. The second hypothesis was that 
this change was not so great among families more closely oriented to Mormon orthodoxy, as indicated by the fact that they began with a temple or civil marriage. Specific elements were studied, such as courtship patterns and problems connected to each during the founding, expanding, and contracting phases of the family cycle.

Findings showed occupational patterns of husbands changed away from agricultural and salesmanship to skilled and semi-skilled. More men married while in school or military service. Housework was more seldom the sole occupation of women at the time of marriage. More wives in each generation had additional occupational responsibilities. Education of mates increased with each group. The predominant religion was Mormonism.

Each successive group tended to have fewer children and to have them in a shorter time. A larger percentage of wives in each group worked outside the home in all three stages of the family cycle. Recreation interests became more passive than active. Roles of family members changed toward the democratic or shared; exclusive roles became less common. Family attitudes became less favorable toward the idea of male superiority, the notion that the best years of life are those of youth, the idea of working mothers, others living with the family, children "talking back" to parents, and marriage across religious lines.

In comparing families which began with temple marriage (considered the most orthodox type of marriage, and used as a criterion in this study in a dichotomy with civil marriage) to those with civil marriages, a higher percentage of wives who were married in temples worked outside the home. Role changes within the 
two groups indicate a greater degree of change toward democracy in families of civil marriage, and more of an exclusive or father-centered role pattern among families which began with temple marriage. Attitude changes were more consistently toward the democratic among "civil" families, and less toward democracy in the "temple" families. "Temple" families generally rated themselves happier than "civil" families.

Canning found, generally, that the observed changes were of lesser degree among the relatively orthodox families than among those not classified as religiously orthodox.

\section{Summary}

The review of the literature emphasizes several significant areas and points of view on women's roles. The facts of earlier marriages, birth control, and longer life span are contributing in a major sense to the need for women to find something to do with their time in middle age after children have left home. Before this century, women spent their entire lives raising their families and there was not time enough to do this job, let alone time to spare.

The problems that arise with the "empty nest" are real to parents. They must not only learn to live a new independent life individually, but they must also learn to live a new life together. This review indicates that there are possibly more unsatisfying relationships between husband and wife at middle age than neighbors and friends might recognize from their vantage point. The fact that a large proportion of women in the older age groups in one study said 
that nothing made them feel useful and important, and that the fact another group in another study were very largely accepting of their roles as homemakers. leads one to realize that there are role conflicts and problems in the middle and older ages that confront each individual. What each chooses to be and to do with this time that is available is not only an individual matter, but is also influenced by the culture and society in which each woman lives.

Factors which seemed to have a large influence on whether or not a woman would go to work were: her reason for employment, the presence of children, the attitude of the husband, and the wife's career orientation. One study indicated that goals for recognition that were formerly associated with homemaking have, perhaps, become linked with paid employment. However, it seems that women rarely seek employment just because of the emptiness of housework. Of major importance is the suggestion that a woman will choose her role in accordance with her self-concept. There is seemingly more adverse effect on marriages in the lower socio-economic strata when the woman works than in the higher occupational and educational categories.

There was evidence that supports the influence of the "romantic cult" in preparing youth for disillusionment in marriage. This romanticism appeared to be more characteristic of males than of females. Adolescent girls appear to be more realistic about what their future will be in the labor market in terms of present day trends than did adolescent boys.

Orientation of girls toward their homemaker role was found to have little or no relation to the orientation of their mothers. This indicates that there are 
other things besides the home and family that influence a girl's concept of her role. There appears to be much disagreement between husbands on the ideal wife role, as well as dissatisfaction with the role performance of wives generally, among the groups studied. This points up another facet of the feminine role conflict. Conflict is evident in the study which showed that mothers had to spend much more time with their small children than they would choose to spend.

The decision of whether to work or not to work was simplified somewhat for mothers by Yarrow's study which suggested that the dominant factor in whether or not a mother would be a good mother was the degree to which she was doing what she wanted to do. If she wanted to work, she would be a better mother if she were working than if she stayed home "out of a sense of duty." By the same token, if she wanted to stay home and had to work, she would probably be a better mother if she could stay home. It would be well to recognize the possibility that there may be some mothers who will not function well as mothers no matter what they choose to do.

The evidence of a trend away from the strictly traditional concept of women's role and the accompanying trend in the family pattern from authoritarian to equalitarian, and the degrees in between, is evident among the older women who felt that it was acceptable for women to work, but that it was a mother's place to be home with small children. The willingness of husband or wife to perform whatever tasks need to be done in the household without attaching gender to the nature of the task, punctuates the equalitarian movement. This attitude is further supported by Axelson's findings which show the husbands of working wives 
as more liberal in their view of the working wife than the husbands of nonworking wives. Mogey's presentation of the nuclear family in which the husband is not an authoritarian symbol, but a participating member gives a new look to changes in the father role as the mother's role is redefined.

As Pineo looked at the changes in marriages from the early and middle years, he found a gradual reduction in marital satisfaction to be general in the group. He observed that acceptance of a liberal ideal might be verbalized by the couples, but that actual behavior would be quite different from the verbalized ideal. The indication of a lag between the conceptualization of an ideal and the actual practicing of the ideal gives a valid picture of the method of social change.

The Canning study describes changes over a 50-year period from fatherdominated families to democratic families living in a community which is culturally similar to that in which this study was done. The indication that the Canning families who were closely oriented to the traditional philosophy of the Mormon church made a less pronounced change toward the democratic family than families who were not so oriented, implies that a strong cultural influence is exerted by l'eglise. This strengthens the position of the influence of a culture on the changes and accepted patterns of roles. 


\section{METHODS}

\section{Sample}

The sample chosen for study was selected from girls married in Weber County, Utah, in 1960, and their mothers. Names of the girls were obtained from the marriage record at the Weber County Court House in Ogden, Utah, and addresses were found in the City Directory for 1963. In order to have a closer range in ages of the daughters, no names were used if the person was 30 years or older when married. This decision was also influenced by the need for each girl to have a mother living who could participate in the study. It was felt that there was a better chance of having more mothers living to take part if the sample were confined to the younger ages.

There were 902 marriage licenses issued in 1960. Divorce rates for the next two years were 44 per cent and 41 per cent, respectively. The City Directory did not list all of the couples who had obtained marriage licenses. Some of these did not use the license that was issued. Others had moved away, or were divorced, or had died. Spanish names were not used because it was felt that another study could well cover some of the minority groups. It was hoped, however, to get some response from the Negro population in the area in order to observe racial trends. Un fortunately, no responses were received from the Negro group in this sample. A total of 275 usable names was obtained for the study. These persons were all those of the 902 original applicants for 
marriage licenses who qualified and who could be located in 1964 .

Inasmuch as there were so many factors working to break down the size of the sample group, it was decided to send questionnaires to the entire 275 daughters hoping to find a sample group of at least 80 mothers who would participate.

* A questionnaire was sent to each daughter and she was asked to fill it out and return it with her mother's name and address so that an identical questionnaire could be sent to the mother. It was felt that an ideal sample would be 100 daughters and 100 mothers.

Usable returns from daughters totaled 132 . There were 7 whose mothers were not living, but who returned their questionnaires even though they had no mother to participate. One of these sent her mother-in-law's address and asked to be included in the study. These returns were used since the comparison was to be between groups rather than individuals. A return of 84 questionnaires from the mothers made a 71 per cent return, and was considered a sufficient number for the study.

The Latter-day Saint religion, more commonly known as Mormon, predominates in the state of Utah. It is likewise the dominant religious and cultural influence in the Ogden area, and was predominant in the sample. Perhaps the work that best describes a community of this type is homogeneous. The structure of the Mormon community is such as to mold the entire group into an exclusive organization. This becomes their basic life pattern to the exclusion of non-members. The function of this church is as a primary group. Each congregation, or Ward, is kept small enough that members know each other in a very familiar situation. 
Their relationships are close, warm, and personal. Thus it is that members of the Mormon church form their reference groups with people of similar values and in the sharing, the values become rather firmly established. The primary group situation is a strong influence in establishing a person's values.

The prevailing philosophy of the church with regard to women is that women's place is in the home. The church is strongly accepting of women's working in the auxiliaries of the church, but the reverse is true of her being employed. In such a culture-bound group as this it would not be supposed that attitudes toward women working would change very rapidly. It could possibly be assumed that the desired pattern encouraged by the culture and the women's actual patterns would be in some disagreement.

$\underline{\text { Instruments and procedures }}$

The Role Conception Inventory developed by Motz for research in social psychology was chosen as the main instrument for this study (21). This instrument has been used several times by others and was adopted for this study on the basis that Motz had established a degree of validity for it. For a time, in preparing this study, the possibility of using the Motz inventory with responses on a Likert scale was considered. Ultimately the inventory was adopted intact, in preference to the scale, because it enabled an evaluation of contradictory or confused role definitions. In other words, this was determined as the best way to find the degree to which a subject was traditional or contemporary in her role perception. 
The Motz Inventory searches attitudes in six areas of behavior: housework, employment, financial support, eare of children, participation in community activities, and schooling. Motz distinguishes between "public" and "personal" in the sense of "self" and "other" orientation. "Public" and "personal" attitudes are examined in each of the six areas, with a total of 24 statements in the women's inventory. A similar evaluation was prepared for men in the Motz study.

The scoring procedure is simple. An individual score is the number of items of each type, either traditional or companionship, checked as applying to the respondent. A person who checked three "traditional" and one "companionship" statements would have a score of " $1-3$, " the score on the left arbitrarily being the companionship score. Scores are changed into major categories by using the following scale which is based on the percentage checked of the total companionship items on the Motz Inventory:

$$
\begin{aligned}
\text { More than } 75 \% & \text { companionship } \\
51-75 \% & \text { moderately companionship } \\
25-50 \% & \text { moderately traditional } \\
0-24 \% & \text { traditional } \quad(24, \text { p. } 465)
\end{aligned}
$$

For example, a person whose responses totaled 60 per cent of the companionship questions would be rated as moderately companionship.

A questionnaire was prepared which included personal information to be compared with responses to the Motz Inventory. This was pre-tested on a group of 23 women after their weekly Relief Society meeting. The Relief Society is the women's auxiliary of the Mormon church, and is open to all women in the church. The age range of this group was the same range that was 
anticipated in the sample. All of the women were married and most had families. It was recognized that a questionnare was needed that would be easy to complete and that would not discourage any respondents. Problem areas were noted in the pre-test, and the questionnaire was altered accordingly. The pre-test group found the original questionnaire to be tedious, particularly a section calling for forced choices. As a result of the pre-test, the forced choice section was eliminated, and the questionnaire was simplified in the hope that the simplification would encourage more responses.

Questionnaires were mailed to each of the daughters with the request that they send the name and address of their mother with their completed questionnaire. The daughter remained unidentified on her questionnaire, and the mother was anonymous on her return also. As questionnaires arrived from daughters, letters were sent to mothers.

From the first group of 275 letters sent to daughters, 18 were returned with address unknown. Of the 119 letters sent to mothers, one was returned with address unknown. A total of 132 returns from daughters and a total of 84 from mothers completed the collection of questionnaires from the sample.

A follow-up was conducted in the mother group using every third return from a daughter for her mother's address, until 30 names were obtained. Of the 30 , one mother was not living, one had no phone, four lived out of town, and 24 had local phones. Letters were sent to three of the out-of-town group. One mother in this group was found to have returned her questionnaire so no letter was sent to her. One who had no phone, but lived in town, was contacted 
in person. Of the 25 who could be contacted immediately, 21 said they had already returned their questionnaires, 3 said they would return them, and 1 asked that another be sent to her. Those contacted by second letter were asked to reply by filling out a questionnaire if they had not, or disregarding the second letter if they had already returned a questionnaire. A telephone conversation with one mother in the follow-up revealed that she and her daughter had discussed the questionnaire before they had filled it out. When asked whether she thought this discussion had changed the way she would have responded she replied, "Oh, no. My daughter and I are completely different." No biases were evident in the non-returning group.

Unisort cards were used for tabulating information so each answer on the questionnaire was given a numerical assignment in order to be entered in the proper place on the cards. Analysis of the data was done using chi-square to determine whether any of the differences were significant, or to what degree they were due to change. Comparisons were made between such things as mothers and daughters and working or not working; mothers and daughters and their Motz score; Motz score and rural and urban childhood; Motz score and education; and others as noted later. It was not the purpose of this study to compare individual mother and daughter responses, but to compare only the responses of the groups. 


\section{FINDINGS}

\section{$\underline{\text { Discussion }}$}

Responses were received from 84 mothers and 132 daughters, All were of the white race. None were received from the Negro race. Ages for daughters ranged from 17 to 33 . Mothers' ages ranged from 39 to 68 . In the mother group, the modal family size was 2 children. The average family had 4 children. Mean age of children in families of the mother group was over 17. Two of the mother group had children under 5 .

Fifteen of the daughters had no children. Forty-six had 1 child, and 69 had from 2 to 4 children. Two of the daughters had children 5 to 7 years old, but these were step-children, or children of a marriage previous to the 1960 marriage.

The anticipated predominance of the Mormon religion in the two groups was confirmed. Figure 1 shows the distribution on religion affiliation for the mothers and daughters, and Figure 2 shows the distribution of the dominant religion in the communities where each group was raised. More of the mothers spent their childhood in communities that were not Latter-day Saint than did the daughters, although the majority of each group grew up in an LDS environment. Mothers working outside of the home totaled 41.4 per cent of the mother group. Daughters working away from home were 35.6 per cent of their group. Of those who were working outside of the home, 80 per cent of the mothers 

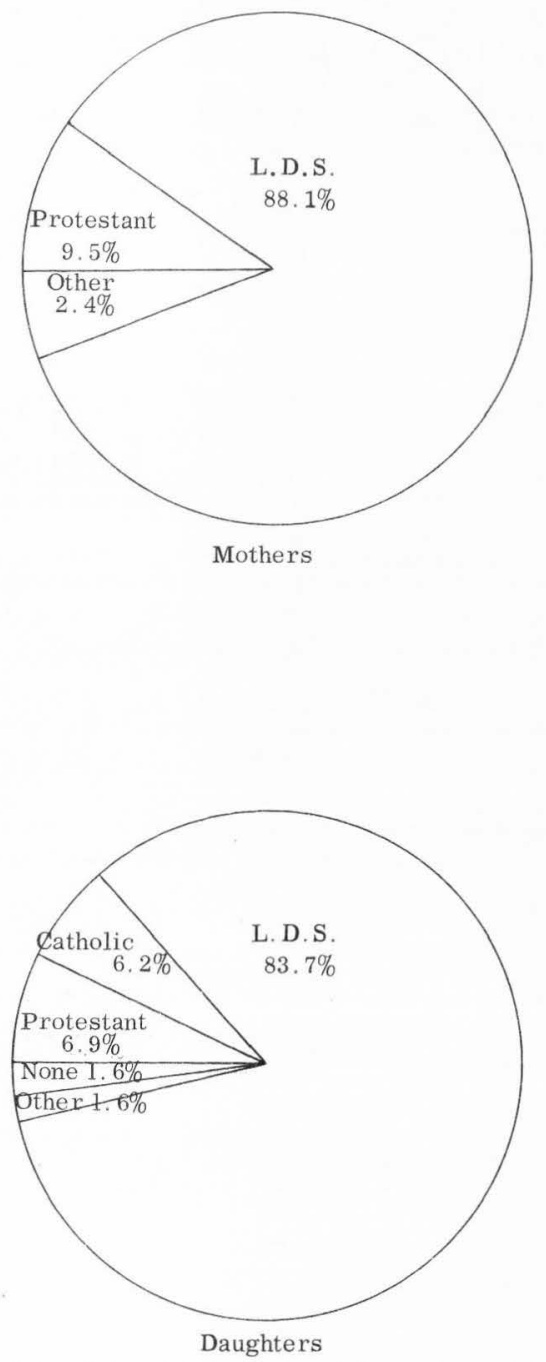

Figure 1. Religious affiliation 

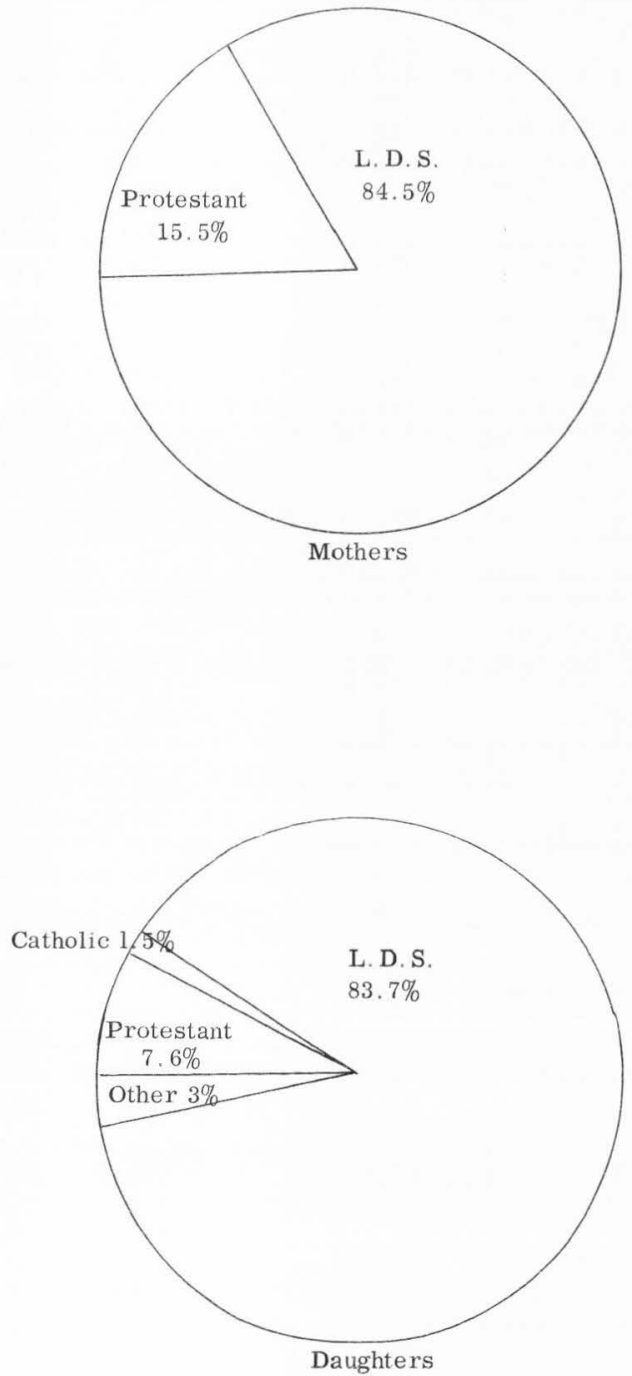

Figure 2. Dominant religion in community where raised 
were glad, and 20 per cent wished they were not working, compared to 70 per cent of the daughters who were glad, and 30 per cent who wished they were not working. Of the mothers who were not working, 90 per cent were glad, and 10 per cent wished they were. In the daughter group, 87 per cent of those not working were glad, and 13 per cent wished they were. According to Yarrow (38) the children would be favored in the families of those who were glad they were not working.

The above comparisons between mothers and daughters and their orientation to work outside of the home show only slight differences in percentages of each group who work away from home. This is in contrast to Canning's (5) findings that during the expanding period, none of his younger group, which would be comparable in ages to the daughter group in this study, worked full time, and 23. 3 per cent worked part time. In the daughter group for this study 29 per cent worked over 15 hours a week, and 23.5 per cent worked 40 or more hours a week away from home. This indicates an increase in numbers of mothers of young families in predominantly LDS environments who are in the work force since 1945 to 1950 , in two similar samples.

There was more satisfaction with work outside the home expressed by the working mother group, but this was only a 10 per cent difference from that expressed by the working daughters, the mothers showing more satisfaction. Conversely, 10 per cent more daughters who were working expressed dissatisfaction with their work away from home than did the working mothers. In terms 
of the prevailing Mormon philosophy that woman's place is at home and in terms of what amounts to a 20 per cent differential, these findings for both groups showed large numbers of employed married women; however, they also showed mothers more contemporary than daughters.

Another comparison with Canning is appropriate. Canning found a higher percentage of wives who were in the orthodox group working outside the home than among his less orthodox group. Of the total responses from both groups there were 27 non-LDS respondents. The scores on Motz were compared to see if there were any differences that were significant in the responses from LDS and non-LDS. No significant differences were noted in this study. Table 2 shows the comparison of LDS and non-LDS responses on the Motz Inventory.

Table 1. Percentages of mothers and daughters employed outside of the home ${ }^{a}$

\begin{tabular}{|c|c|c|c|c|}
\hline \multirow[b]{2}{*}{ Group } & \multicolumn{4}{|c|}{ Hours per week away from home working } \\
\hline & $1-14$ & $15-29$ & $30-39$ & 40 or more \\
\hline Daughters & $5 \%$ & $4 \%$ & $0.8 \%$ & $23.5 \%$ \\
\hline Mothers & 1. $2 \%$ & $8.2 \%$ & $4.8 \%$ & $25.0 \%$ \\
\hline
\end{tabular}

The table above shows 9 per cent of the daughters in part-time employment using the arbitrary point of 29 hours or less for part-time work; 9.4 per cent of the mother group were similarly engaged. On a slight difference existed here. 
Table 2. Comparison of LDS and non-LDS scores on the Motz Inventory ${ }^{\mathrm{a}}$

\begin{tabular}{lccc}
\hline Group & $\begin{array}{c}\text { Moderately } \\
\text { companionship }\end{array}$ & $\begin{array}{c}\text { Moderately } \\
\text { traditional }\end{array}$ & Traditional \\
\hline Non-LDS & $15 \%$ & $48 \%$ & $37 \%$ \\
LDS & $10 \%$ & $51.4 \%$ & $38.4 \%$
\end{tabular}

${ }^{\mathrm{a}}$ None of the relationships compared in this table was statistically significant at the 5 per cent level.

Figure 3 shows the comparisons between the education of mothers and daughters and their husbands. There was a noticeable increase in the number of years spent in school from the older to the younger generation. There was also evidence that the wives in the older group had more education on the average than did their husbands.

Table 3. Hours spent in activities outside the home by mothers and daughters, expressed in percentages of responses ${ }^{\mathrm{a}}$

\begin{tabular}{|c|c|c|c|c|c|}
\hline \multirow[b]{2}{*}{ Group } & \multicolumn{5}{|c|}{ Hours per week spent in activities outside the home } \\
\hline & None & $1-5$ & $6-10$ & $11-15$ & Over 15 \\
\hline Mothers & $20.7 \%$ & $46.3 \%$ & $29.3 \%$ & $4.9 \%$ & $1.2 \%$ \\
\hline Daughters & $23.2 \%$ & $52.0 \%$ & $19.0 \%$ & $5.6 \%$ & $0.8 \%$ \\
\hline
\end{tabular}




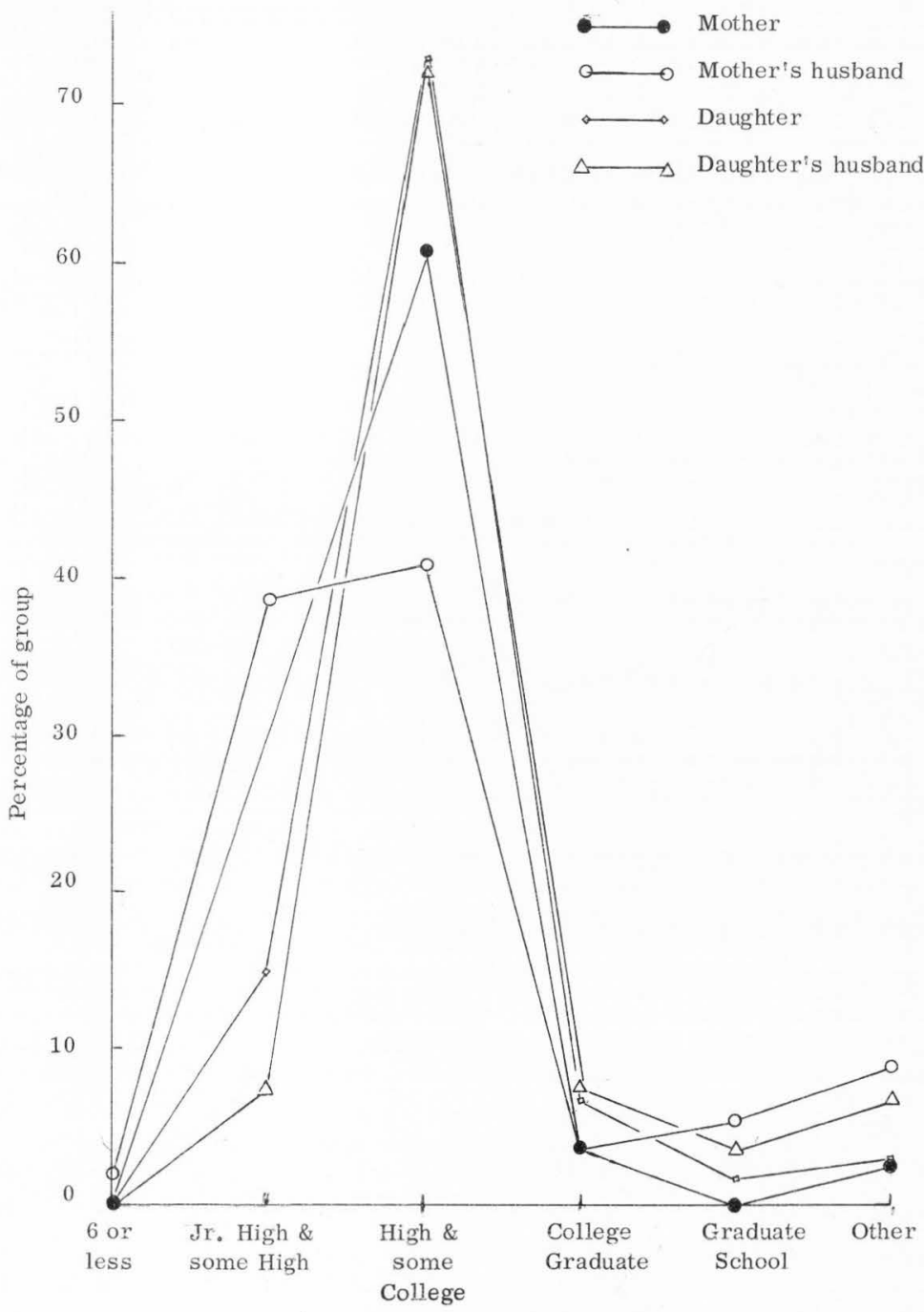

Figure 3. Comparison of education--mothers, daughters and husbands 
There was a slight observed difference between the number of mothers who had no activities outside the home compared to the daughters who had none, 3.5 per cent more of the daughters falling into this category than mothers (see Table 3). More daughters than mothers spent from 1 to 5 hours a week away from home in activities, but as the hours increased, the total percentages for the mother group increased, and there was a sharp decline in daughter activity. A tendency was evident for the daughters to have a larger number in their group with no activities outside the home at all, although this difference was a small one. The large percentage of mothers and daughters who had from 0 to 2 hours of activities away from home per week may indicate a high degree of satisfaction with the homemaker role. supporting Steinman's findings. In the case of women who work full time, it may indicate a lack of time for anything but homemaking duties and work. Possibly her work is an attempt as Weiss and Samelson indicated to find feelings of worth, or as Brayshaw described it, in reaction to the "empty nest," a seeking for fulfillment now that the family is raised. These families with low activity outside the home may be "happier" as Canning found, and not feel a need for other contacts.

If a woman has very small children she may be too tied down to get away. One of the daughters who had two small children ages 26 months and 6 months, replied to the request for total number of hours per week suually spent in activities outside the home, "None, I would like to get away for awhile before I go crazy. " This comment evidenced some role conflict for this young mother and in a small way corroborates Gray's research. 
Responses to the question concerning where each individual was raised, whether rural, small town, or urban, tallied as shown in Table 4. This table calls attention to the population shift from farm to city. Note the same percentage of daughters raised in rural areas as mothers raised in cities. This strong shift to the city was not accompanied by any similarly strong shift in role concept of wives in the sample, however. There were no significant differences in the responses to the Motz inventory between mothers and daughters in the rural, small town, and urban brackets. A chi-square analysis of childhood environment and role perception as either work oriented or not work oriented showed no significant differences. This means, perhaps that there are other influences operating to shape the sample's definitions of homemaker role.

Table 4. Comparison of childhood environment of mothers and daughters whether rural, smali town, or urban ${ }^{a}$

\begin{tabular}{lccc}
\hline Group & $\begin{array}{c}\text { Population } \\
\text { under 2500 } \\
\text { Rural }\end{array}$ & $\begin{array}{c}\text { Population } \\
2500-9,999 \\
\text { Small town }\end{array}$ & $\begin{array}{c}\text { Population } \\
\text { over 10,000 } \\
\text { Urban }\end{array}$ \\
Mothers & $63.1 \%$ & $10.7 \%$ & $26.2 \%$ \\
Daughters & $26.6 \%$ & $15.2 \%$ & $55.2 \%$ \\
& & \\
${ }^{2} \begin{array}{l}\text { None of the relationships compared in this table was statistically significant } \\
\text { at the } 5 \text { per cent level. }\end{array}$
\end{tabular}


Several significant findings developed in the mother group. A comparison of rank in parental family with work orientation showed a distribution that was significant at the 05 level with 2 degress of freedom. The first born appeared to be more work oriented than the middle or youngest child. No significant distribution was found for the daughters. There were significant differences between the children's ages and the wife's work orientation for the mother group. This was significant at the 02 level with 1 degree of freedom. This finding substantiates Glenn's findings that the presence of young children is a factor in a wife's decision to work.

Also significant was the relation between the husband's attitude toward women working and the wife? s work orientation, a relationship found by Weil. This occurred at the .02 level with 3 degrees of freedom for mothers, and at less than .001 with 3 degrees of freedom for the daughter group. Husband's attitude was the most important single influence on the role definition by this group of women. The years the wife was previously employed and her work orientation were significantly related at the 001 level with 2 degrees of freedom. If she had been employed before marriage her attitude toward working outside of the home was less traditional.

The basic hypothesis of this study was supported by finding no significant trend away from the traditional role toward the contemporary role between the mother generation and the daughter generation. The response of mother and daughter to the Motz Inventory showed no significant differences. The patterns of group responses were very similar. No person in either group scored as "companionship" on the inventory. Of those who scored "moderately companionship, "four mothers were working and four were not; three daughters were working and three were not. The graph in Figure 4 illustrates the percentage comparison of group scores on the 


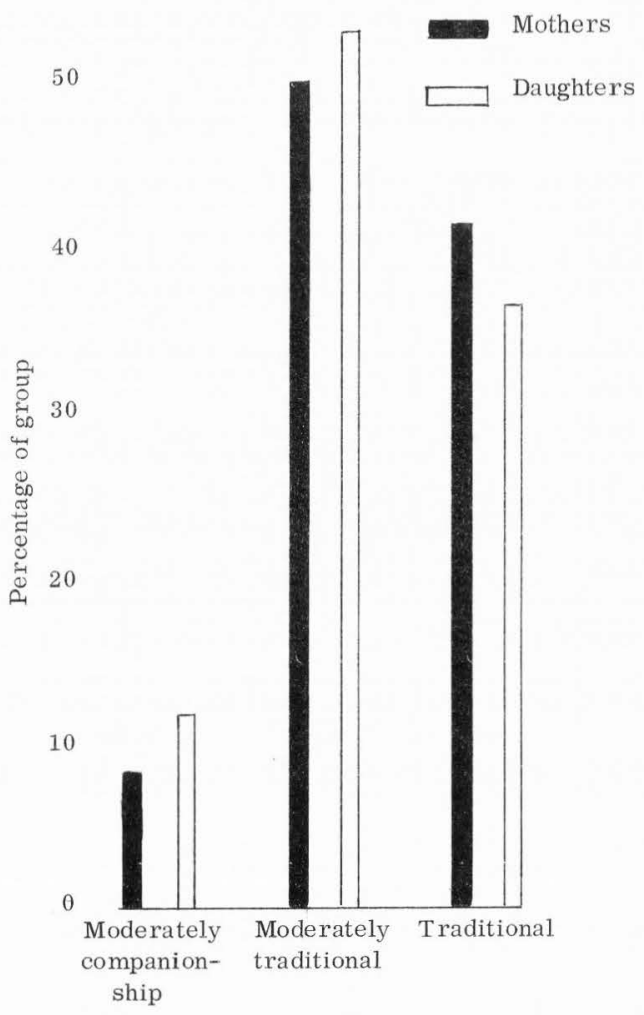

Figure 4. Comparison of mother's and daughter's scores on Motz Inventory (see Appendix p. 80$)$. 
Motz Inventory. The comparison by percentages showing a larger percentage of daughters rated as "moderately companionship" and "moderately traditional" and fewer as "traditional, " indicates a possible trend away from the traditional concept of woman's role. At the same time it indicates a possible trend for the daughters to become more traditional, since it is not possible to determine in one study alone which direction the trend is moving. Payne found a trend moving in this direction from young adolescent to older adolescent and this could possibly be a continuation of the trend he observed. The differences in group responses were not significant in the chi-square analysis since they could have occurred by chance 95 times out of 100 .

It appeared that the two generations of women perceived their roles in much the same manner with only slight variations which in most cases were not great enough to be measurable. This finding is unlike that of Schneider who found mothers $^{s}$ and daughters role orientations to be unrelated. It must be assumed that some uniting factor is operating in the sample to cause such uniformity of response. The strongest factor of this nature that is immediately obvious is the influence of religion on this homogeneous sample. It appeared logical to assume that this factor was the primary cause of the identical responses received on the Motz Inventory. It is interesting to note that religion was influential in this sample but rural-urban differences were not.

The fact that both generations of women responded in such similar manner lent greater significance to the few differences that did occur in response to the Motz Inventory Group responses to individual questions on the inventory are pictured in Figures 5 and 6. The greatest differences in the "companionship" 


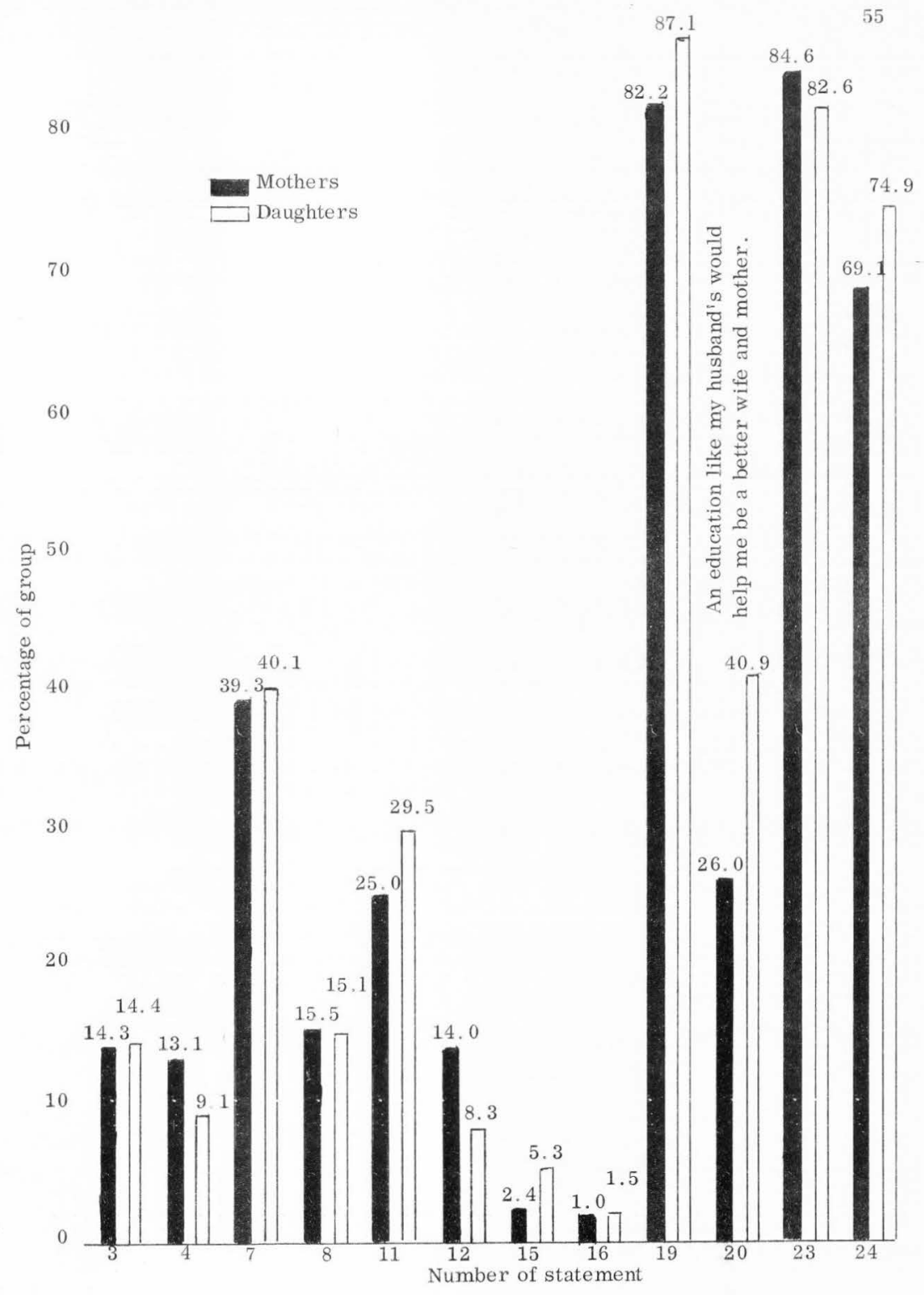




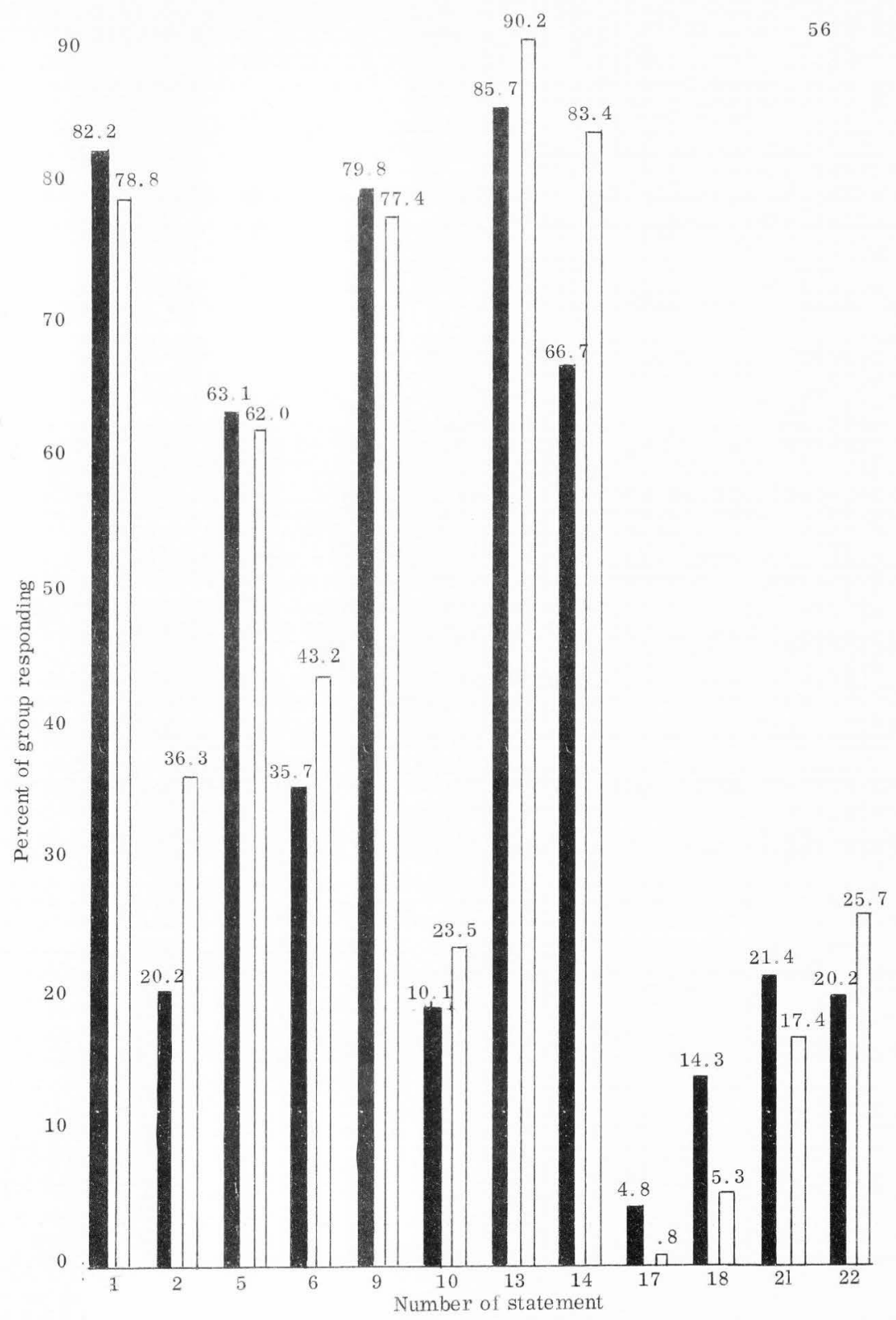


responses (Figure 5) was found on statement number 20 which reads, "I think an education like my husband's would help me to be a better wife and mother." This was responded to by 26.2 per cent of the mothers compared to 40 per cent of the daughters. In a chi-square computation of mother and daughter responses and non-responses to the statement, this was significant at the .05 to .02 level with 1 degree of freedom. Responses to all other "companionship" statements were not significantly different. Responses to statement number 20 were understandably lower for the mother group than for the daughter group, and the reason can be seen in Figure 3. There was a greater difference between the education of the husband and wife in the mother group and so there would be little desire on the part of the mothers to bring their educational level down in order to have an education "like their husband's." On the other hand the education of the daughter group and husbands was more nearly the same, and was greater for the husbands from the trade school to college graduate on to graduate school. Thus it appears that there would be more challenge to the wives in the younger group to have an education more like their husband's.

The two sample groups were close in their responses to nearly all statements that were rated "traditional." (See Table 6.) The greatest differences occurred on statement 14 , which reads, "I think it should be my duty as a wife to do practically all the housework." This was checked as applicable to 66.7 per cent of the mothers and 83 per cent of the daughters. This was significant at the 01 level with 1 degree of freedom. A significant finding here indicated that the daughters at this point in their lives are inclined to be more traditional 
than their mothers. This attitude could be the result of their stage of family development. Their families are very small and very young, and it is possible that much idealization of the perfect and proper family is influencing the younger group at this point. The mothers on the other hand are either entering or are in the "empty nest" stage with families grown and self-sustaining, and have approached the inventory with a somewhat different point of view on the subject of housework.

The findings just discussed for the daughter group oppose Payne's findings for adolescent girls showing them to be more equalitarian in their perception of adult roles. Whether or not our sample would have responded as Payne's did at the same age can only be speculation. Payne indicated that the younger adolescents were more equalitarian than the older adolescents. In view of this trend in his study, and assuming that the attitudes of this sample and Payne's sample could have been similar at younger ages (and there is not much basis for such an assumption), the trend away from the equalitarian concept of the adult role of these girls underwent a marked change from the late adolescence into their third year of married life.

The heavy response to a traditional concept of homemaker raised a question as to whether there were any of Mogey's families in the sample. The findings indicated that in the housework area, at least, the father in our sample was not a participating member of the household. It appears that in this study as in the Canning study, the LDS homes tend to be more authoritarian than equalitarian. Christensen's findings (6) differed from these in that she found them more equalitarian. 
Another difference occurred in response to statement 2: "It would be wrong for me to earn money and help support the family when times are normal." The mothers' responses totaled 20.2 per cent compared to a 35.3 per cent response from daughters. In a chi-square comparison of responses and nonresponses between mothers and daughters, this difference was significant just under the .01 level with 1 degree of freedom. The greater response from daughters shows them to be somewhat more traditional than their mothers on this aspect of roles. Perhaps the difference in responses between the two groups was the result of the daughters idealizing as mentioned before, and their effort to establish the ideal family that their religion describes, and of the mothers over the years achieving a less traditional point of view as their families became self-sufficient. The fundamental difference possibly was the different phases of family development that the two generations found themselves in.

The fact that responses to statement 2 in both groups did not represent the majority of the group tends to indicate some acceptance of women working. The greater response from daughters is a slight indication that they are more traditional than their mothers. The non-responding mothers have possibly found much enjoyment in their freedom to choose to work or not. Some of them may have been trying to fill the void of the "empty nest" described by Brayshaw. Others may have found that goals for recognition formerly linked with homemaking were not linked with employment as discussed by Hatch and Hatch. Still others might have been seeking for ways to feel worthwhile as per Weiss and Samelson. 
The two traditional statements responded to least often by both groups were numbers 17 and 18. Number 17 reads: "It is nice for an unmarried girl to have a college education but a married wo man would not have much use for one." Eight per cent of the daughters responded to this, compared to 4.8 per cent of the mothers. Statement 18 says: "Although it would be nice for me to further my education, I really don't think I would have much use for it." Response to this statement was 5.3 per cent for daughters and 14.3 per cent for mothers. These were low responses, and because they were low, seemed to indicate the general feeling that a college education or furthering her education is valued for a married woman by the members of the sample. This was an area in which both mothers and daughters had a point of view in common which was not a part of the traditional concept of homemaker, although nearly 10 per cent more of the mothers responded than daughters. This difference is not significant, but could indicate the beginning of a trend away from tradition on the part of the daughter group.

On the "companionship" statements, less than 2 per cent of each group responded to number 15: "I don't see why housework should be my job any more than my husband's," The daughters responded less frequently than mothers. Statement 16 evoked a sparse response also: "There is no reason that a married woman should be any more tied down to housework than her husband should be." The proportionate response to this statement was 2.4 per cent for mothers, and 5.3 per cent for daughters. These were the expected responses in agreement with the traditional response indicating that it was a wife's duty to do practically all the housework 
Over 80 per cent of both groups responded to statement 19 which concerned the need for a married woman to be as well educated as a married man in order for her to be a better companion to her husband. This was an expected response because of the former sparse responses to the traditional statements concerning education for women.

The response to statement number 23 was also over 80 per cent for both groups. This statement said. "Every married woman should have some kind of outside interests so that she and her husband have more in common." There appeared to be some conflict between the responses to this statement and the number of hours spent per week in activities outside the home. Sixty-four and seven tenths per cent of the mothers said they spent 0 to 5 hours a week in activities outside the home, and of these, 32.1 per cent said they had none. Of the daughters, 74.5 per cent said they spent from 0 to 5 hours, and of these, 30 per cent said they spent none. It would have seemed more logical that a larger number of women had activities outside of the home when both groups appeared to feel that outside interests were necessary, but it may be that the way this statement was worded prevented some from including interests they enjoy such as reading and music and creativity that does not require many hours away from home

Responses to the statement which read: "A mother with preschool children ought to be at home with them and ought not to be away from them for more than 15 hours a week," showed the following. 
Table 5. Attitudes of mothers and daughters toward employment of mothers whose children are in school ${ }^{\mathrm{a}}$

\begin{tabular}{lrrrc}
\hline Group & $\begin{array}{c}\text { Strongly } \\
\text { agree }\end{array}$ & Agree & Disagree & $\begin{array}{c}\text { Strongly } \\
\text { disagree }\end{array}$ \\
Mothers & $67 \%$ & $28.5 \%$ & $1.0 \%$ & $3.5 \%$ \\
Daughters & $53 \%$ & $36.0 \%$ & $7.0 \%$ & $3.0 \%$ \\
\hline
\end{tabular}

${ }^{a}$ None of the relationships compared in this table was statistically significant at the 5 per cent level.

Mothers and daughters were strongly in agreement with this statement. Ten per cent of the daughters and 4.5 per cent of the mothers disagreed with the statement. Here was a recurrence of the mothers and daughters similarity of response throughout the study. On this statement, their unanimity falls into the traditional category. This reinforces the trend for the mothers'and daughters' perception of role to be similar

Another statement read: "A mother whose children are in school should be able to work away from home more than 30 hours a week if she wants to do so." (See Table 5.) Responses to this statement were divided between agree and disagree in both the mother and daughter groups; 53 per cent of the mothers agreed compared to 65 per cent of the daughters. Disagreement was expressed by 47 per cent of the mothers and 35 per cent of the daughters. The traditional response on this statement would have been to disagree. This appears to be an area where the groups are together in the slight transition away from the traditional concept. 
Table 6. Attitudes of mothers and daughters toward employment of mothers of preschool children ${ }^{a}$

\begin{tabular}{|c|c|c|c|c|}
\hline Group & $\begin{array}{c}\text { Strongly } \\
\text { agree }\end{array}$ & Agree & Disagree & $\begin{array}{l}\text { Strongly } \\
\text { disagree }\end{array}$ \\
\hline Mothers & $1 \%$ & $52 \%$ & $33 \%$ & $15 \%$ \\
\hline Daughters & $5 \%$ & $60 \%$ & $28 \%$ & $7 \%$ \\
\hline
\end{tabular}

The secondary hypothesis that the actual and stated role patterns would probably disagree was supported by the large numbers of married women who were employed as opposed to the LDS teaching that women belong in the home. Further support was given by the perception of role by both groups as traditional and moderately traditional showing only slight changes in role perception, but 10 per cent fewer daughters working than mothers showed their actual role in some disagreement with their stated role. Final substantiation was given to this hypothesis by the responses to statement 23 on the Motz Inventory. Over 80 per cent of both groups stated that they needed to have outside interests, yet the hours of activity spent outside the home are low for the majority of the women.

There was no provision on the questionnaire for requesting results of the study, but 60 women asked for results to be sent, and there were 3 personal notes enclosed as well as one three-page letter. Many women commented by writing on the questionnaire itself, saying they had enjoyed participating and would 
appreciate a report of the findings. The responses indicate this to be an area of vital interest to women.

\section{Summary}

The sample was a homogeneous group because of the predominance of the LDS religion which exerts a strong cultural influence on its members.

The basic hypothesis was supported. In the sample selected for study there was no significant trend away from the traditional role toward the contemporary role in either the mother or daughter groups and there was no significant difference in the attitudes of the mothers and daughters. Daughters tended to score slightly less traditional on the Motz Inventory, but were significantly more traditional on who should do the housework and whether or not she should earn money when times are normal. The daughters were significantly less traditional in response to the need for an education like their husband's in order to be a better wife and mother.

The secondary hypothesis was substantiated by finding some discrepancy between actual and stated role patterns. In terms of the cultural image of woman's place in the home, as taught by the LDS church, large numbers of married women in the sample were working. Further support was given by the response in favor of outside activity as contrasted with the actual numbers of hours spent outside the home in activities. Final support was given this hypothesis by the perception of role by both groups as traditional and moderately traditional, showing only slight changes in role perception, but in reality, only 10 per cent fewer daughters 
than mothers were working even though more daughters had younger children at home. The minor hypothesis that there will be no significant influence upon women's contemporary or traditional role perception by certain specific variables was supported by the failure to find any significant relationships between the Motz score in either sample group and any of the minor variables.

Other findings included a significant relationship between rank in parental family with work orientation, ages of chidren, and wife's work orientation, in the mother group.

A significant relationship in both groups between husbands ${ }^{~}$ attitude toward women working and the wife's work orientation was established. The husbands' attitude appeared to be the most influential force operating in the study to determine attitude of the wife toward employment.

Daughters were significantly more traditional about who should do the housework than mothers were. Mothers were more inclined than the daughters to sanction the wife? $\mathrm{s}$ working in normal times.

Slightly more satisfaction with working was registered by the mother group. There was only a small difference in work orientation of the two groups which seemed to be an indication of a move by the daughters toward the traditional role for young mothers.

Education of the younger husband and wife was more similar than for earlier marriages. In the mother group the wives were better educated than the husbands. A strong shift in childhood environment from rural to urban was not accompanied by a related shift in role perception. There was agreement in both 
the groups that the mother of pre-school children should be at home with them. Opinion was divided in both groups on whether mothers with children in school should work or not.

There were no observable differences between responses and scores of the LDS and non-LDS groups. 


\section{CONCLUSIONS, IMPLICATIONS AND RECOMMENDATIONS}

\section{Conclusions}

The two generations of women in this study defined their roles as homemakers in nearly identical terms. Their concept of a woman's role was predominantly traditional. This perception of role did not agree with the present involvement of women in our country in a new role as a modern homemaker in a more nearly equalitarian family.

The fact that the expressed role of the sample was traditional did not alter the fact that women in the sample were working at all ages, and in this respect there was role-ideal conflict. Women in this culture had been caught up in and were participating in the move to factory and office, but were evidently not ready to define their roles in that light. This was a typical pattern of response to cultural lag in which behavior precedes changes in ideals (31). Changes in social practice begin slowly and are expressed by actions and participation long before they are acknowledged verbally. As soon as the majority affirms a practice, then the ideal loses its value.

Young mothers? role definitions were evidently influenced by the ideal. Even though nearly as many of them were employed as were the older mothers, they seemed not to have been influenced in their stated role by the practice of their being employed. The presence of small children in the home of the daughter group probably influenced their verbal response. 
No differences were observed among the LDS and non-LDS in any areas of response. It would be interesting to have further investigation as to why there was not much difference between these two groups.

The minor hypothesis that there would be no significant influence upon a woman's role perception by several selected variables was supported in several categories. There was a statistically significant relationship between birth order in parental family and work orientation in the mother group. Another significant area was the relationship between children's ages and wife's work orientation for the mother group. In addition, there was a relationship between the husband's attitude toward women working and the wife's work orientation for both generations of women, as well as a relationship between the years the wife was previously employed and her work orientation.

Further validation is needed, but this study shows that mothering is important to women. These women valued the traditional roles of wife and mother. The most important single influence on their definition of the ideal role for women was the attitude of the husband.

These findings are inconclusive and are confined to the selected group in this study. Further research would be needed to establish these findings as valid for any other population.

\section{Implications}

Women's role today is the product of constant change throughout the ages. The fact that women are working outside the home today is not a fad. It has 
roots that lie deep in history. Women in America have always contributed in some manner to the support of the family and home. The fact of women's earning is not new, but the transplanting of her employment from home to places outside the home is new (30).

It would be difficult to retreat from the pattern of change in which women have been and are involved. Groves tells us that deliberate efforts to turn back the clock in matters of this sort have never worked $(12, p, 269)$. It would be just as impractical to push the feminine mystique (13) to the exclusion of mothering. If we feel any responsibility for the children in our society, then we must have someone to care for them properly. In our culture, the mother is the most appropriate person for the job. This is an important function. We value motherhood much as it has always been valued for women, but in addition, we recognize the value of the individual, the need to respect individuality in the variations each woman may choose to make her role performance personally rewarding.

The lack of a model for today's women constitutes both a challenge and a problem (8)--a problem in that general approval as a woman cannot be found no matter what she chooses to do, and a challenge in that she is relatively free to design her own methods of validation. Herein lie some of the strongest impli cations of this study. Motherhood must be accepted. It was highly valued by the group studied. But for the modern women there must be motherhood combined with other interests and perhaps greater activity whether this takes the form of employment, services to the church or community, pursuit of hobbies, or recreation. 
If this trend in role performance for women is to continue in our society, then society must come to the aid of the women. First of all, there must come the willingness to accept individuality. In addition, there necessarily must be a serious look at day care center facilities, programs, and financing in order to assure the finest supplemental care for children. Employers need to reexamine the contribution of working mothers to the economy of the country and adjust required working hours to better fit her responsibilities as a mother.

Educational institutions need to be willing to help girls design study programs that will be adaptable to the mother role as well as career needs. Older mothers, whose families are leaving the home, who are interested in furthering their education need courses of study outlined in accordance with their special needs.

The final responsibility belongs to the individual woman to be herself, but she will not find true satisfaction until society extends more acceptance to the fact of individual differences in women.

\section{Recommendations}

Suggestions for further research as emphasized by this study include a similar study done in a group more representative of the total population, either in the United States, or the Mormon Church, a similar study among minority groups, a similar study using grandmothers instead of mothers for comparisons, and another similar study in 20 years from now on the third generation to follow the trends suggested in this research.

Other suggestions include a study of father "participation" in these 
families as opposed to authoritarian role, a longitudinal investigation of the definitions of roles through each family phase to see if Payne's observations (28) carried through from adolescence, a comparison of women's IQ with a desire to be more active outside of the home, and a study of anxieties in this sample group as Gray (15) did. 


\section{LITERATURE CITED}

(1) American woman, report of the president's commissionon the status of women. United States Government Printing Office, Washington D. C. 1963.

(2) Axelson, Leland J. The marital adjustment and marital role definitions of husbands of working and nonworking wives. Marriage and Family Living 25:189-195. 1963.

(3) Blood, Robert O. and Robert L. Hamblin. The effect of the wife's employment on the family power structure. Social Forces 36:347-352. 1958 .

(4) Brayshaw, A. Joseph. Middle-aged marriage: idealism, realism, and the search for meaning. Marriage and Family Living 24:358-364. 1962.

(5) Canning, Ray Russell. Changing patterns and problems of family life in Provo, Utah 1905-1955. Unpublished PhD dissertation. University of Utah Library, Salt Lake City, Utah. 1956.

(6) Christensen, Sandra J. Comparisons of marital role conceptions of men and women. Unpublished M.S. Thesis. Utah State University, Logan, Utah. 1963.

(7) Collier, Robert P. Today's working women. In Contemporary women-a symposium sponsored by College of Family Life. Utah State University, Logan, Utah. February 14, 1963.

(8) Contemporary Women, A Symposium. Sponsored by the College of Family Life. Utah State University. February 14, 1963.

(9) Cuber, John F., and Peggy B. Barroff. The more total view: relationships among men and women of the upper middle class. Marriage and Family Living 25:140-144. 1963.

(10) Dornbusch, Sanford M., and David M. Heer. The evaluation of work by females. American Journal of Sociology 63:27-30.

(11) Fand, Alexander. Sex role and self concept; a study of the feminine sex role as perceived by eighty-five college women for themselves, their ideal woman, the average woman, and men's ideal. Unpublished $\mathrm{PhD}$ dissertation. Cornell University Library, Ithaca, New York. 1955. 
(12) Farber, Seymour M. and Roger H. L. Wilson. The potential of woman. A symposium. McGraw-Hill Book Co., Inc., New York. 1963. 328 pp.

(13) Friedan, Betty. The feminine mystique. W. W. Norton and Company, Inc., New York. 1963. 410 pp.

(14) Glenn, Hortense M. Attitudes of women regarding gainful employment of married women. Journal of Home Economics 51:247-252. 1959.

(15) Gray, Horace. Trapped housewife. Marriage and Family Living 24:179-182. 1962.

(16) Groves, Ernest R. The American woman. Revised and enlarged edition. Emerson Books, Inc, New York. 1944. 465 pp.

(17) Handbook on women workers 1962. Bulletin 285. United States Department of Labor, United States Government Printing Office, Washington, D. C. 1963.

(18) Hatch, Mary G. and David L. Hatch. Problems of married working women as presented by three popular working women's magazines. Social Forces 37:148-153. 1958 .

(19) Hobart, Charles W. Disillusionment in marriage, and romanticism. Marriage and Family Living 20:156-162. 1958.

(20) Kephart, William M. The family, society, and the individual. HoughtonMifflin Company, Boston, Massachusetts. 1961. $690 \mathrm{pp}$.

(21) Komarovsky, Mirra. Woman in the modern world, their education and their dilemmas. Little, Brown and Company, Boston, Massachusetts. 1953. $319 \mathrm{pp}$.

(22) Leser, C. E. V. Trends in women's work participation. Population Studies 12:100-110。 1958.

(23) Mogey, J. M. A century of declining paternal authority. Marriage and Family Living 29:234-239. 1955 .

(24) Motz, Annabelle. A role conception inventory; a tool for research. American Sociological Review 17:465-476. 1952.

(25) Nye, F. Ivan. Maternal employment and marital interaction: some contingent conditions. Social Forces 40:113-119. 1961. 
(26) Nye, F. Ivan and Lois W. Hoffman. The employed mother in America. Rand McNally and Company, Chicago, Illinois. 1963.

(27) Nye, F. Ivan and Evelyn MacDougall. The dependent variable in marital research. Pacific Sociological Review 2:67-70. 1959.

(28) Payne, Raymond. Adolescent's attitudes toward the working wife. Marriage and Family Living 18:345-348. 1956.

(29) Pineo, Peter C. Disenchantment in the later years of marriage. Marriage and Family Living 23:3-11. 1961.

(30) Rollins, Mabel A. Monetary contributions of wives to family income in 1920 and 1960. Marriage and Family Living 25:226-227. 1963.

(31) Ross, H. Laurence. Perspectives on the social order, readings in sociology. McGraw-Hill Book Company, Inc., New York. 1963. 467 pp.

(32) Schneider, Lynn Ronald. The relationship between identification with mother and home or career orientation in women. Unpublished PhD dissertation. Columbia University Library. 1962.

(33) Steinman, Anne. The vocational roles of older married women. Journal of Social Psychology 54:93-101. 1961.

(34) Stuber, Marilyn Cook. A study of feminine roles from the husband's point of view. Unpublished M.S. Thesis. University of Nebraska Library. 1961.

(35) Weil, Mildred W. An analysis of factors influencing married women's actual or planned work participation. American Sociological Review 26:91-96. 1961 .

(36) Weiss, Robert S, and Nancy Morse Samelson. Social roles of American women: their contribution to a sense of usefulness and importance. Marriage and Family Living 20:358-366. 1958.

(37) Womanpower. National Manpower Council. Columbia University Press, New York. 1957. 371 pp.

(38) Yarrow, Marian Radke, Phyllis Scott, Louise Leeuw, and Christine Heinig. Child rearing in families of working and non-working mothers. Sociometry 25:121-140. 1962 . 
A PPENDIX 
COLLEGE OF FAMILY LIFE

PHYLLIS R. SNOW, DEAN

DEPARTMENT OF FAMILY

AND CHILD DEVELOPMENT
DARYL CHASE, PRESIDENT

LOGAN, UTAH, 84321

Copy of letter sent to daughters

Dear

We are conducting a study, through the College of Family Life at Utah State University, to learn how women feel about the jobs they perform at home and at work. It is hoped that the results of this study will enable us to have a better understanding of married women and their problems in our world today. We are asking the cooperation of a selected group of women who were married in 1960 in Weber County, and that is why we have sent you this letter. We will also need to know if you have a mother living whom you think would be willing to participate in this project

All this study will require from you will be to give us your mother's name and address, and for each of you to fill out a short questionnaire that takes 10 or 15 minutes to complete. If you are willing to cooperate in the study, please fill out the enclosed questionnaire, following directions carefully. Send it to us by return mail in the enclosed envelope so that we may contact your mother as soon as possible and send her a copy of the questionnaire.

We are asking for your mother's name only for the purpose of setting up the study so that we can compare two generations of women. In reporting results, no names of individuals will be used, and all information concerning individuals will be regarded as strictly confidential. The only way an individual will appear in the study is as a member of a group.

Thank you very much for your cooperation. If you are interested in the results of this study, please let us know and we will send them to you.

Sincerely yours,

Don Carter, Head

Dept. of Family and Child Development 


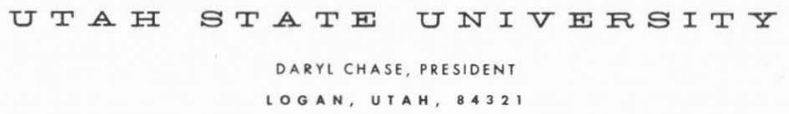

You have a daughter who was married in 1960 who has consented to participate in a study being conducted in the College of Family Life at Utah State University. This study will evaluate the way women feel about the jobs they perform at home and at work. It is hoped that the results of this study will enable us to have a better understanding of married women and their problems in our world today. We are asking the cooperation of a selected group of women who were married in 1960 in Weber County and their mothers. This is why you are receiving this letter.

Your daughter's responses to our questionnaire will not be useful unless you are willing to respond also. All that this study will require from you is to fill out the enclosed questionnaire which take from 10 to 15 minutes to complete. Please complete the questionnaire, following directions carefully, and send it to us by return mail in the enclosed stampled, addressed envelope.

In the report of results, no names of individuals wili be used, and ail information will be regarded as strictly confidential. The only way an individual will appear in the study is as a member of a group.

You are the only person who can give us the information we need for a successful survey, so, you see, your response is vitally important. We hope you enjoy taking part.

Thank you so very much for helping us. If you are interested in the results of the study, please let us know and we will see that you receive them.

Sincerely yours,

Don Carter, Head

Dept. of Family and Child Development

Enc: Questionnaire

Return envelope 
Study of Women's Attitudes

Please fill out the following questionnaire as completely as possible, being sure to follow directions carefully. Sincere and frank answers are what we need in order to obtain valid information to be used in scientific research. There are no right or wrong answers. The responses should be your own convictions.

Your name is not on the questionnaire, so your answers will be absolutely anonymous. We are not interested in individual answers, but only in the response of the entire group being studied.

Date of your birth Race

Number of children Their ages

PLEASE MARK BELOW THE COMMENT THAT FITS YOU BEST. PLACE AN X TO INDICATE YOUR CHOICE: ("working" means some kind of EMPLOYMENT FOR A WAGE OR SALARY)

I am working, and I'm glad

I am working, but I wish I were not.

I am not working, and I'm glad.

I am not working, but I wish I were.

If you are presently working:

What is your occupation?

How many hours a week to you spend at the above job AT HOME?

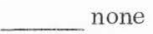

1 to 14 hours

15 to 29 hours

30 to 39 hours

40 or more hours

How many hours a week to you spend earning AWAY FROM HOME: none 
1 to 14 hours

15 to 29 hours

30 to 39 hours

40 or more hours

Who cares for your children while you are away from home?

No children at home

No children at home while I am away

A relative, with pay

A relative, without pay

A neighbor, with pay

A neighbor, without pay

Other (please specify)

PLEASE INDICATE BELOW, THE ACCUMULATED TOTAL NUMBER OF YEARS YOU HAVE EVER BEEN EMPLOYED:

Have never been employed

Have been employed for less than 2 years total

Have been employed between 2 and 5 years total

Have been employed between 5 and 10 years total

Have been employed more than 10 years

DRAW A CIRCLE AROUND THE NUMBER OF YEARS OF SCHOOLING YOU HAVE COMPLETED

123456789

Grade school

\section{4}

High School
1234

College
1234

Post Graduate Other

What is your religious affiliation?

Protestant

Jewish

Other

Catholic

L. D. S .

None 
What was the predominant religion in the environment in which you were raised?

Protestant
Catholic
the child in a family of

PLEASE INDICATE THE TOTAL NUMBER OF HOURS PER WEEK YOU USUALLY SPEND IN ACTIVITIES OUTSIDE THE HOME. (Example: PTA, church, clubs, volunteer or community services.)

Number of hours per week

Where were you raised? On a farm or in a community under 2500 population A community of 2500 to 9,999 A city of 10,000 to 40,000 A city over 40,000

DRAW A CIRCLE AROUND THE NUMBER OF YEARS OF SCHOOLING YOUR HUSBAND HAS COMPLETED:

$\begin{array}{lllll}123456789 & 1234 & 1234 & 1234 & 1234\end{array}$

Grade School High School College Graduate School Trade School Other

What is your husband's occupation?

My HUSBAND'S attitude toward married women working is:

He strongly likes the idea of married women working.

He likes the idea of married women working.

He dislikes the idea of married women working.

He strongly dislikes the idea of married women working.

PLEASE CHECK THE RESPONSE THAT FITS YOUR OPINION OF THE STATEMENTS BELOW:

A mother with pre-school children ought to be at home with them and ought not to be away from them for more than 15 hours a week. 
Strongly agree

Agree
Disagree

Strongly disagree

A mother whose children are in school should be able to work away from home more than 30 hours a week if she wants to do so.

Strongly agree

Agree
Disagree

Strongly disagree

PLEASE MARK AN X IN FRONT OF THE STATEMENTS BELOW WHICH APPLY TO YOU OR EXPRESS YOUR POINT OF VIEW. DO NOT MARK ANY STATEMENTS THAT DO NOT APPLY TO YOU. MARK AS MANY OR AS FEW AS YOU THINK APPLY TO YOU.

1. The wife should help support the family only when it is absolutely necessary.

2. It would be wrong for me to earn money and help support the family when times are normal.

3. Marriage is a partnership in which the wife should share the responsibility of supporting the family with the husband whenever possible.

4. I think it should be my responsibility as much as my husband's to help support the family whenever I am able.

5. Wives who don't have to work should not.

6. My working might be all right while my husband is unemployed, but I don't think I should work after he is employed full time.

7. A married woman should work if she is able to and enjoys work.

8. I would like to work if possible even after my husband is employed, because I am happier when I work.

9. Nothing should be more important to a mother than to see that her children are well fed, clothed, properly clean, and kept out of danger.

10. If, as a mother I fed, dressed, cleaned and watched over the children, I would feel I had done my duty toward them.

11. The mother together with the father should place the personality needs of the children before their daily physical care. 
12. As parents, my husband and I should put more emphasis on the social development of our children than on cleanliness and routine.

13. The wife should consider it her job to prepare meals and keep the house clean.

14. I think it should be my duty as wife to do practically all the housework.

15. There is no reason that a married woman should be any more tied down to housework than her husband should be.

16. I don't see why the housework should be my job any more than my husband's.

17. It is nice for an unmarried girl to have a college education, but a married woman would not have much use for one.

18. Although it would be nice for me to further my education, I really don't think I would have much use for it.

19. A married woman should be as well educated as a married man, because education helps her to be a companion to the children and husband.

20. I think an education like my husband's would help me to be a better wife and mother.

21. Women generally enjoy talking about their children, recipes, and strictly women's topics. That is the way it should be.

22. I think I would much prefer talking to the girls about children, recipes, and housekeeping--the things women talk about--than about world affairs and things like that.

23. Every married woman should have some kind of outside interests so that she and her husband have more in common.

24. I think it is important for me to have some kind of outside interests because I am a better companion to my husband. 